\title{
Halide-bridged polymers of divalent metals with donor ligands - structures and properties
}

\section{U. Englert *}

Institute of Inorganic Chemistry, RWTH Aachen University, Landoltweg 1, 52074 Aachen, Germany. Fax:+ 49- 2418092288; Tel: +49 241 8094666; E-mail: ullrich.englert@ac.rwth-aachen.de

Dedicated to Professor Fausto Calderazzo at the occasion of his 80th birthday

\section{Contents}

Abstract

1. Introduction

2. Chain polymers

2.1 Chains from polyhedra with coordination number four

2.2 Chains from polyhedra with coordination number five

2.3 Chains from corner-sharing octahedra

2.4 Chains from edge-sharing octahedra

2.5 Chains from face-sharing octahedra

2.6 Chains from polyhedra with coordination number greater than six

2.7 Chains incorporating different types of polyhedra

3. Polymers with additional crosslinking

3.1 Polymers with halide bridges in two dimensions

3.2 Polymers with crosslinking donor ligands

4. Polymers with higher metal halide content

4.1. Chains incorporating unsubstituted metal halide fragments

4.2. Double chains

4.3. Ribbons and sheets incorporating unsubstituted metal halide fragments

5. Concluding remarks

Acknowledgements

References

Abbreviations: 2,2'-bipy, 2,2'-bipyridine; 4,4'-bipy, 4,4'-bipyridine; 8-aad, 8-azaadenine; amim, 4-(2-aminoethyl)imidazole; ampym, 2-aminopyrimidine; biu, biuret = carbamylurea; bpm, bipyrimidine; bppz, 2,5-bis(2-pyridyl)pyrazine; chd, 1,2-cyclohexanediol; cyclam, 1,4,8,11-tetraazacyclotetradecane; dadpm, 4,4'-diaminodiphenylmethane; dap, 1,3-diaminopropane; dmpd, 2,2dimethylpropane-1,3-diamine; dmso, dimethyl sulfoxide; dpdo, 4,4'-dipyridyl- $N, N^{\prime}$-dioxide; $\mathrm{H}_{2}$ dapd, 2,6-diacetylpyridine dioxime; hat, 1,4,5,8,9,12-hexaazatriphenylene; hmpa, hexamethylphosphoramide; hmt, hexamethylentetramine; im, imidazol; MOF, metalorganic framework; NIToPy, 2(2-pyridyl)4,4,5,5-tetramethyl-4,5-dihydro-1H.imidazol-1-oxy.3- $N$-oxide; ox, oxalato; phen, phenanthroline; py, pyridine; pym, pyrimidine; pyz, pyrazine; pyzca, pyrazine-2-carboxylate; taa, thioacetamide; thf, tetrahydrofuran; trz, 1,2,4-triazolato anion 


\begin{abstract}
Coordination polymers and organic-inorganic hybrid materials represent an area of very active research. Halide-bridged polymers of divalent transition or post-transition metals coordinated to donor ligands are reviewed. The article is organized according to structural features of the compounds: The main sections of chain polymers, crosslinked systems and networks of high metal halide content are subdivided according to connectivity aspects. Structural trends are highlighted and the correlation between chemical composition and topology on the one hand and derived properties and dynamics on the other hand is discussed.
\end{abstract}

Keywords: Organic-inorganic hybrid materials; Coordination polymers; Halide bridges; Structural chemistry

\title{
1. Introduction
}

Binary halides of divalent metals such as $\mathrm{CdCl}_{2}$ with its layer structure or the cubic mineral fluorite $\mathrm{CaF}_{2}$ are treated in introductory texts on general and inorganic chemistry. Advanced students will encounter more complex solids, for example the hexagonal perovskite $\mathrm{CsCuCl}_{3}$. From a formal point of view, coordination of donor ligands to the metal cations can "cut out" [1] and stabilize ligand-substituted fragments of these inorganic lattices. This intuitive concept of "dimensional reduction" has been discussed in detail by Tulsky and Long [2]. The earlier literature also offers several beautiful examples for systematic studies in this direction: Nieuwenhuyzen and Wilkins described a series of complexes formed by $\mathrm{CdBr}_{2}$ and the donor ligands dmso and water, from a metal halide rich $2 \mathrm{D}$ sheet structure over $1 \mathrm{D}$ chain polymers to mononuclear, i.e. zero-dimensional ionic compounds [3]. Sobota and coworkers investigated the aggregation of $\mathrm{MnCl}_{2}$ in thf solutions and the equilibrium between oligonuclear and polymeric species [4]. Continuing along this line of argument, one can in principle imagine every composition in between the inorganic metal halide and the fully ligand-substituted, mononuclear species such as an hexaaqua metal complex $\left[\mathrm{M}\left(\mathrm{OH}_{2}\right)_{6}\right]^{2+}$.

The present contribution will attempt to review those polymers of divalent metals which still feature bridging halides in addition to the donor ligands: These compounds provide a meeting ground between the fields of coordination compounds and classical inorganic and ionic solids.

As usual for review articles, restrictions have to be made. The metals under consideration are transition metals or main group metalloids whereas derivatives of alkaline or alkaline earth metals have not been covered [5]. The review is arranged by topological criteria: The introduction is followed by a section on one-dimensional polymers which is subdivided according to the building blocks involved and their connectivity. After the 1D cases, two-dimensional polymers are addressed in which the crosslinks may either be due to additional halide bridging in the second dimension or to ditopic donor ligands. The final section is devoted to polymers in which the metal halide content is high, i.e. in which the donor ligands are either "diluted" along the chains or in which ribbon-like metal halide backbones with low ratio between donor ligands and cations are formed. Throughout this review, the donor ligands are mostly but not exclusively small organic molecules bonded to the metal via $\mathrm{N}, \mathrm{O}, \mathrm{S}$ or $\mathrm{P}$. It is a frequent side effect of restrictions that the borders are fuzzy: In addition to the above-mentioned donor atoms, alternative and less popular attachment points for the ligands may well exist. Occasionally, the question about which interaction should be considered bonding will arise, and hence coordination numbers and topology of the structure under discussion may result ambiguous. Finally, the restriction to polymers of divalent metals cannot be more meaningful than the concept of oxidation states in general.

The dynamics of halide-bridged polymers of divalent metals and the driving force for their formation have been an aspect of our own research during the last decade. Crystallization has often been challenging, for us as well as for other groups. Several authors reported problems with crystallization [6-10]. Consequently, structure determination based on powder data is relatively frequent among the compounds discussed in this contribution [9, 11-15]. Additional motivation for addressing this bona fide unreviewed subject stems from the fact that literature about these polymers and their structures is scattered over time and journals. Under these conditions, it is no surprise that space group ambiguities, isomorphous structures and duplications have occasionally remained undetected. Hopefully, this article will provide an overview and helpful crosslinks . $^{\S}$

\footnotetext{
$\S$ The figures in this review have not been copied from earlier publications but are directly based on CIF files from our own diffraction experiments or retrieved from the Cambridge Structural Database [16] and produced with CrystalMaker [17] unless stated otherwise.
} 


\section{Chain polymers}

The most popular metal coordination geometries in one-dimensional polymers with neutral donor ligands and at least one bridging halide are compiled in Scheme 1, together with the sections in which these compounds will be addressed. Corner-sharing tetrahedra represent the prototype for tetracoordinated cations (Scheme 1a). Fivefold metal coordination is encountered in squarepyramidal or trigonal-bipyramidal corner-sharing polyhedra (Scheme 1b) or in edge-sharing tetragonal pyramids (Scheme 1c). Hexacoordination is most frequent: Octahedra around the cations may share common vertices in neutral, cationic or anionic chains (Scheme 1d-f), they can be linked via edges (Scheme 1g-i) or join through common faces (Scheme 1j). In the latter case, stoichiometry requires the presence of two bridging halides and an additonal bridging (neutral) donor.<smiles>[Y]N(CC)C([X])(C)C</smiles>

a

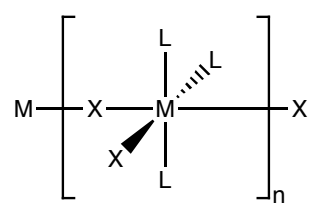

d

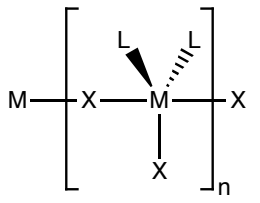

b

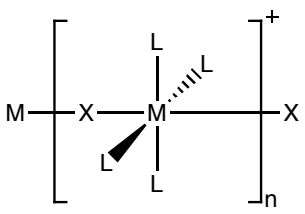

e

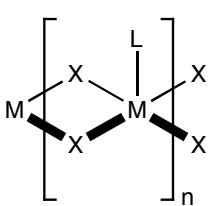

c

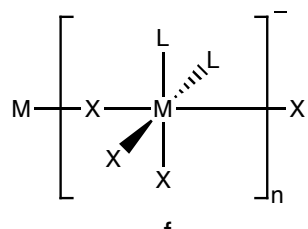

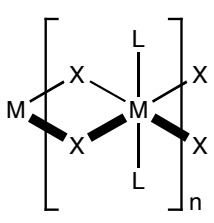

g

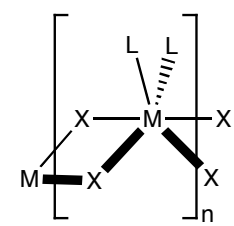

h

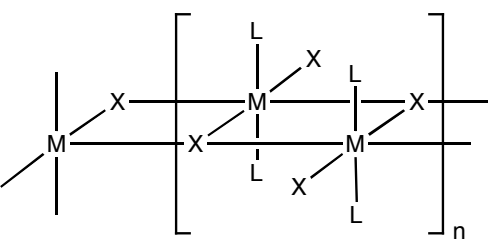

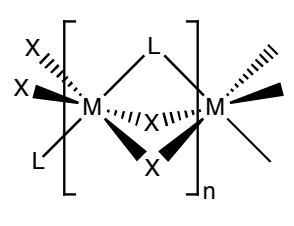

j

Scheme 1. Prototype geometries for chain polymers; $M=$ divalent metal, $X=$ halogen, $L=$ donor ligand. a) Corner-sharing cations with coordination number four, covered in section 2.1. Chains from five-coordinate corner-sharing (b) or edge-sharing (c) cations (section 2.2). Chains from vertex-sharing octahedra as covered in section 2.3: Neutral (d), cationic (e), and anionic (f) chains. Chains from edge-sharing octahedra (section 2.4), with all halides bridging two cations and the donor ligands in trans (g) or cis (h) configuration or with triply bridging and terminal halide ligands (i). j) Chains from face-sharing octahedra (section 2.5).

Building blocks with higher coordination number and chains combining different geometries are less frequent and are shortly covered in sections 2.6 and 2.7, respectively. Anisotropy is an inherent property of chain polymers: Needle-shaped crystals prevail among the documented morphologies for the compounds introduced in this chapter.

\subsection{Chains from polyhedra with coordination number 4}

Chromium trioxide [18] represents a classical inorganic compound in which four-coordinated metal centers join via cornersharing to infinite chains. Structurally characterized derivatives of divalent metals which feature coordination of additional donor ligands are restricted to $\mathrm{Hg}(\mathrm{II})$ [19-22], [23-26] with its general preference towards lower coordination numbers and to $\mathrm{Zn}$ (II), [27, $28]$ a rather small divalent cation. Fig. 1 shows a prototypic example, the thf adduct to $\mathrm{ZnCl}_{2}$.

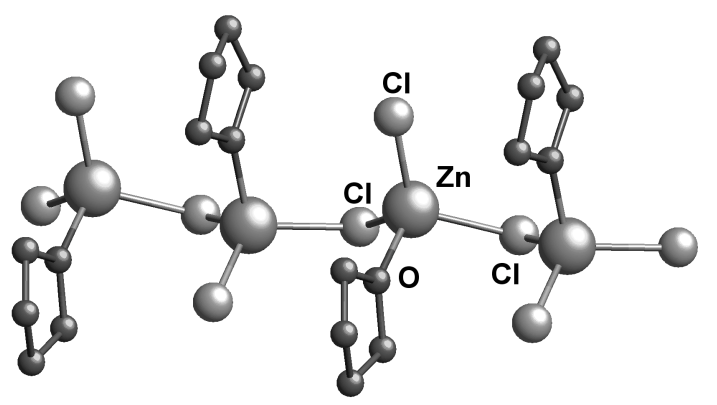

Fig. 1. Neutral chain of corner-sharing tetrahedral $\mathrm{Zn}(\mathrm{II})$ cations in $[\mathrm{Zn}(\mu-\mathrm{Cl}) \mathrm{Cl}($ thf $)]$. Structural result from ref [27]. 
For $\mathrm{Zn}(\mathrm{II})$, halide-bridged polymers are generally rare ( $c f$. section 2.4). For divalent mercury, coordination number 5 is more abundant and will be discussed in the following section 2.2 .

\subsection{Chains from polyhedra with coordination number 5}

The main connectivity patterns discussed in this section comprise corner- and edge-sharing polyhedra. The former topology will be addressed first.

Penta-coordination is often associated with soft degrees of confomation and structural flexibility. The experimentally observed coordination geometries can be classified as polyhedra along a hypothetic Berry pseudorotation path from trigonalbipyramidal to square-pyramidal [29]. The classical Jahn-Teller ion $\mathrm{Cu}(\mathrm{II})$ is most prominent among the corner-sharing connectivities (cf. Scheme 1b): Several examples of square-pyramidal $\mathrm{Cu}$ complexes have been described in which a bridging chloride [30-33] or bromide [34] represents a ligand in the base plane of one cation and in the apical position of a neighbouring cation. Sharing of a common vertex between adjacent polyhedra has also been encountered in copper complexes with coordination geometry in-between trigonal-bipyramidal and square-pyramidal, again both for chloro $[35,36]$ and bromo bridges [37]. Divalent copper is an obvious candidate for magnetic studies: Magnetic coupling within the polymer chains is generally weak [38]. Cases of ferromagnetic [34, 37] as well as of antiferromagnetic interactions [35, 36] have been described.

The structure of catena- $\{\mu$-chloro-semicarbazide-copper(II) $\}$ [39] provides an instructive example for the ambiguities associated with connectivity criteria, in particular when Jahn-Teller ions are involved. If the rather long $\mathrm{Cu}-\mathrm{Cl}$ interaction of more than $3.14 \AA$ is considered a bond, the compound should be classified in section 2.4 rather than here.

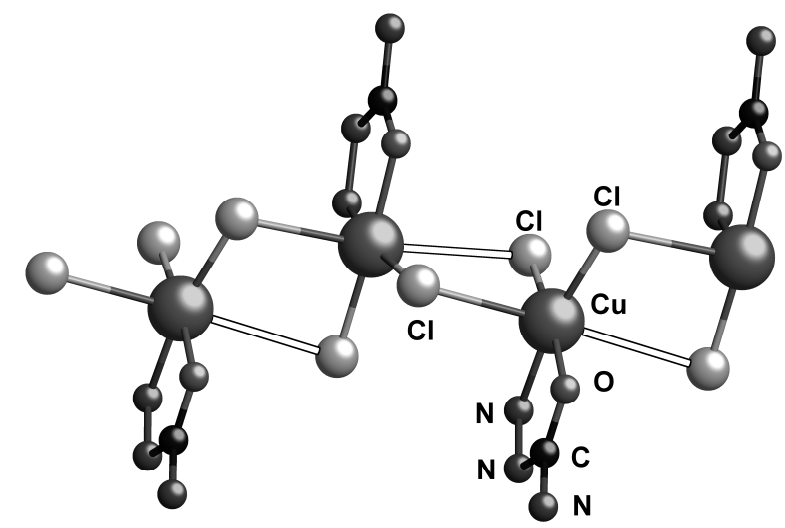

Fig. 2. Chain of $\mathrm{Cu}(\mathrm{II})$ cations in catena- $\{\mu$-chloro-semicarbazide-copper(II) $\}$. The open $\mathrm{Cu}-\mathrm{Cl}$ bond is longer than $3.14 \AA$. Structural result from ref [39].

Edge-sharing according to Scheme 1c represents the alternative connectivity for penta-coordinated polyhedra. In $[\mathrm{Hg}(\mu-$ $\left.\mathrm{Br})_{2}\left(3,5-\mathrm{Cl}_{2} \mathrm{py}\right)\right]_{\infty}[40]$ cations in square-pyramidal coordination share edges in their base planes; all apical ligands point to the same side of the polymer chain as shown in Fig. 3.

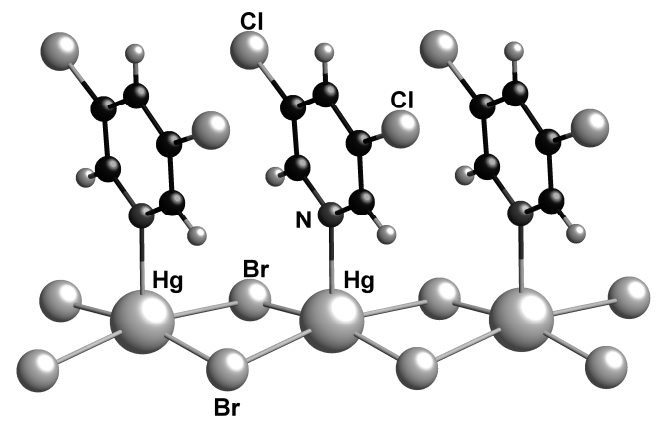

Fig. 3. Edge-sharing of square-pyramidal $\mathrm{Hg}(\mathrm{II})$ cations in $\left[\mathrm{Hg}(\mu-\mathrm{Br})_{2}\left(3,5-\mathrm{Cl}_{2} \text { py }\right)\right]_{\infty}$. Structural result from ref [40]. 
Examples with other metals in fivefold coordination are rare. The $\mathrm{Mn}(\mathrm{II})$ [41] and $\mathrm{Cd}(\mathrm{II})$ [42] derivatives of dimethylphenylphosphine feature chains of square pyramids with the apical ligands in an anti arrangement. The compounds are isomorphous and have been reported independently by different groups. The manganese chain polymer is shown in Fig. 4; it was obtained by direct reaction from metal powder and ligand.

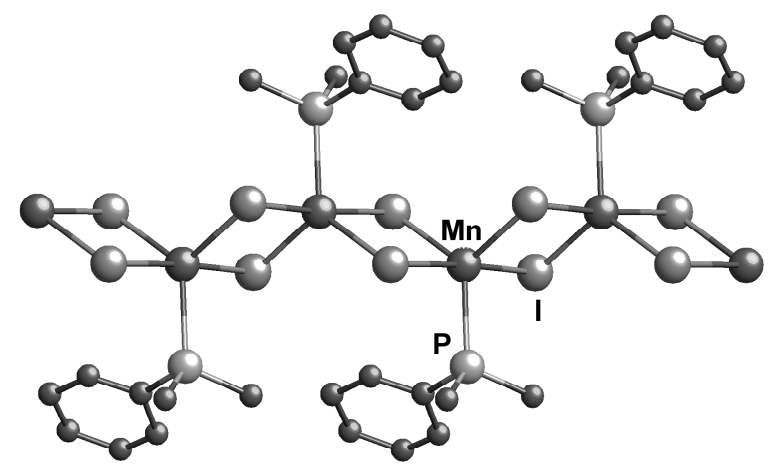

Fig. 4. Neutral chain of edge-sharing square-pyramidal $\mathrm{Mn}(\mathrm{II})$ cations in $\left[\mathrm{Mn}(\mu-\mathrm{I})_{2}(\mathrm{PPhMe})_{2}\right]_{\infty}$. Structural result from ref [41]

\subsection{Chains from corner-sharing octahedra}

The connectivity patterns for the compounds in this section are shown in Scheme 1d-f: A single halide ligand bridges between two metal centers with octahedral coordination geometry. The binary halide $\mathrm{BiF}_{5}$ represents a classical inorganic example with this topology [43]. As far as divalent cations with additional donor ligands, the topic of this review, are concerned, this type of chain polymer is rather rare.

Neutral chain polymers have been found for two structurally related diethylentriamine complexes of cadmium [44] and copper [45] and for a cadmium derivative of the zwitterionic ligand dimethylglycine [46].

Examples for structurally characterized cationic chains are the cyclam complexes $\left[\mathrm{Co}(\mu-\mathrm{Cl}) \mathrm{cyclam} \mathrm{ClO}_{4} \cdot \mathrm{MeOH}[47](\mathrm{Figure}\right.$ 5), the related $\left[\{\mathrm{Cu}(\mu-\mathrm{Cl}) \mathrm{cyclam}\}_{2}\right] \mathrm{CdCl}_{4}[48]$ and the compound $\left[\mathrm{CuCl}(\mathrm{amim})_{2}\right] \mathrm{Cl}_{2} 2 \mathrm{H}_{2} \mathrm{O}$ [49] in which two bidentate $N$ donor ligands instead of the cyclam macrocycle occupy the positions in the equatorial plane of the pseudooctahedron.

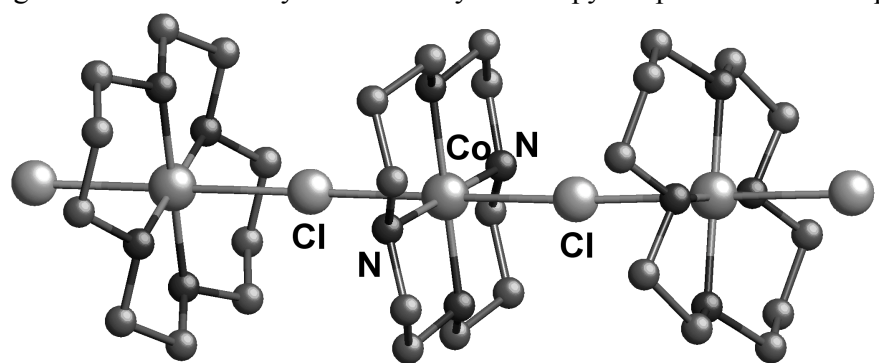

Fig. 5. Cationic $\left[\{\mathrm{Co}(\mu-\mathrm{Cl}) \text { cyclam }\}^{+}\right]_{\infty}$ chain in $[\mathrm{Co}(\mu-\mathrm{Cl})$ cyclam $]\left[\mathrm{ClO}_{4}\right] \cdot \mathrm{MeOH}$. Structural result from ref [47].

For the bromo-bridged $\mathrm{Ni}$ complex of the macrocyclic ligand $\alpha, \alpha^{\prime}$-2-bis $\{(5,7$-dimethyl-1,4,8,11-tetraazacyclotetradeca-6-yl)o-xylene $\}$ a phase transition between room temperature and $100 \mathrm{~K}$ with marked changes both in the structure and in the magnetic properties has been observed [50].

Chains from $\left\{\mathrm{Mn}(\mu-\mathrm{Cl}) \mathrm{Cl}_{2}\left(\mathrm{OH}_{2}\right)_{2}\right\}^{-}$units featuring bridging and terminal chloro ligands have been structurally characterized with imidazolium [51] (Fig. 6) and with methylammonium [52, 53] counter cations. The conformation of the anionic polymer in both salts is the same, and the lattice parameters in chain direction amount to ca $9.1 \AA$, i.e. twice the $\mathrm{Mn} \cdots \mathrm{Mn}$ distance, in both compounds.

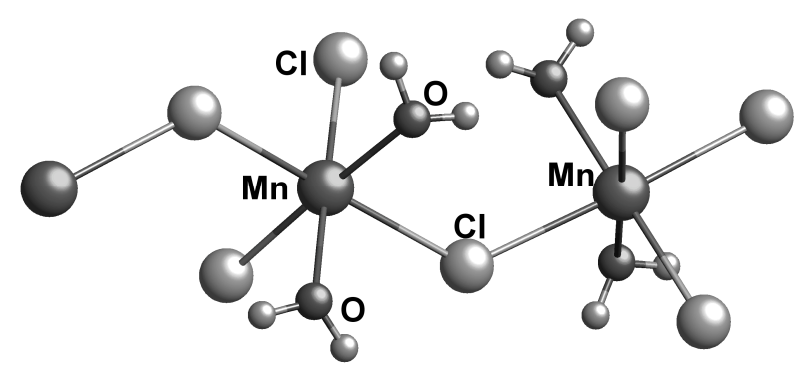

Fig. 6. Anionic chain of corner-sharing octahedral $\mathrm{Mn}(\mathrm{II})$ cations in $\left\{\mathrm{imz}\left[\mathrm{Mn}(\mu-\mathrm{Cl})\left(\mathrm{Cl}_{2}\left(\mathrm{OH}_{2}\right)_{2}\right]\right\}_{\infty}\right.$. Structural result from ref [51]. 
Corner-sharing between neighbouring octahedra is not restricted to the formation of one-dimensional chains; more popular are arrangements with four bridging halide ligands in two perpendicular directions. Such a connectivity pattern with the general composition $\left[\mathrm{ML}_{2} \mathrm{X}_{4 / 2}\right]_{\infty}^{2}$ is shown in Scheme 3a, and the resulting layer structures are addressed in chapter 3.1.

\subsection{Chains from edge-sharing octahedra}

When four halide ligands per metal are engaged in bridging between cations along the polymer chain the connection between neighbouring octahedra may be accomplished either in a trans fashion according to Scheme $1 \mathrm{~g}$ or, alternatively, by placing the donor ligands in cis geometry (Scheme 1h).

We will first address the trans-configured chains. The underlying geometry is encountered in the binary halide $\mathrm{NbCl}_{4}[54]$. In this inorganic solid shorter bonding intermetal distances and longer nonbonding separations alternate along the polymer strand whereas in the structures relevant for this review no direct metal-metal bonds and no formation of cation pairs are observed. Chains built up from trans edge-sharing octahedra represent a very frequent structural motif and historically the first among the connectivity patterns treated in this review. As early as 1936, Harker [55] and almost simultaneously Bijvoet and McGillivray [56] published the crystal structure of copper(II)chloride dihydrate. This prototype structure is shown in Fig. 7.

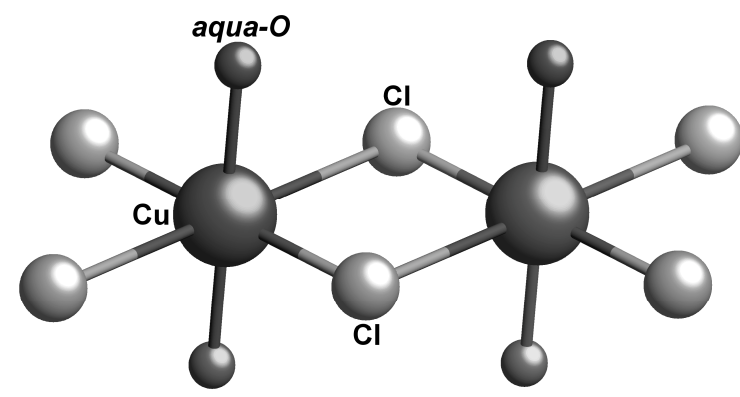

Fig. 7. Chain in $\left[\mathrm{Cu}(\mu-\mathrm{Cl})_{2}\left(\mathrm{OH}_{2}\right)_{2}\right]_{\infty}$. Structural result from ref [56].

Early studies concerning the magnetic properties of diaquabis( $\mu$-halogeno)metal(II) polymers as either Ising- or Heisenbergchains [57] were devoted to the trimethylammonium chloride adducts. This structure type is able to accomodate first-series transition metal cations of rather different size: The $\mathrm{Cu}$ [58], Co [59], Mn [60], Ni [61, 62] and Fe [63] compounds with bridging chloride as well as the Fe derivative with bromide bridges [64] have been structurally characterized. All compounds are isomorphous in space group Pnma; the only exception is the copper chain polymer which crystallizes in the subgroup $P 2_{1} / c$ with a unit cell of similar dimensions.

Already in 1938, Mellor and Coryell [65] associated the structure type shown in Fig 7 with "more organic" ligands. They suggested that the short lattice parameters of ca $3.65 \AA$ in $\mathrm{CoCl}_{2} \mathrm{py}_{2}$ and ca $3.73 \AA$ in $\mathrm{MnCl}_{2} \mathrm{py}_{2}$ might be due to an analogous connectivity, assuming "each metal ion sharing four coplanar chloride ions in pairs and holding two pyridine molecules at right angles to the plane of the chloride ions". In 1957, Dunitz finally confirmed that this structure model was correct for the cases of $\mathrm{CuCl}_{2} \mathrm{py}_{2}$ and $\mathrm{CoCl}_{2} \mathrm{py}_{2}$ [66]. Among the early X-ray studies on related compounds is that for the chain polymer $[\mathrm{Cd}(\mu-$ $\left.\mathrm{Cl})_{2}(\text { biu })_{2}\right]_{\infty}$ by Nardelli et al. [67].

Although X-ray diffraction is doubtlessly the most widespread method to establish the nuclearity and connectivity for the structures discussed in this review, spectroscopic methods have also been used successfully in order to distinguish between different coordination polyhedra and to establish the nuclearity of the compounds under study: Ferraro and Davis applied farinfrared spectroscopy to the 4,4'-bipyridine adducts of metal dihalides and found both halide and bipy bridging for the networks based on $\mathrm{Mn}^{2+}, \mathrm{Fe}^{2+}, \mathrm{Co}^{2+}, \mathrm{Ni}^{2+}, \mathrm{Cu}^{2+}$ and $\mathrm{Cd}^{2+}$ cations; they also postulated a tetrahedral chain structure with bridging bipy and terminal halides for $\left[\mathrm{ZnCl}_{2}\left(4,4^{\prime}\right.\right.$-bipy)] [68], in perfect agreement with later structural results [69]. Goldstein and coworkers studied complexes formed upon coordination of donor ligands to metal dihalides by far-infrared and Raman spectroscopy [70-73] It should be kept in mind that at the beginning of these experiments, in 1970, the Cambridge Structural Database [16] only comprised roughly 10000 structures. Among other assignments, Goldstein et al. correctly identified $\mathrm{CdX}_{2} \mathrm{py}_{2}$ as octahedralpolymeric for $\mathrm{X}=\mathrm{Cl}, \mathrm{Br}$ and as tetrahedral-mononuclear for $\mathrm{X}=\mathrm{I}[72]$.

Derivatives of the late transition or of the post-transition elements have been the objects of several systematic studies by our group. The main focus was to establish the range of existence for chain polymers of general formula $\left[\mathrm{M}(\mu-\mathrm{X})_{2} \mathrm{py}_{2}\right]_{\infty}(\mathrm{M}=\mathrm{divalent}$ metal cation, $\mathrm{X}=\mathrm{Cl}, \mathrm{Br}$, I and py = pyridine-type ligand). In the case of $\mathrm{Zn}(\mathrm{II})$, octahedral coordination with four or more chloro ligands is very rare; octahedral tetrabromo or tetraiodo complexes have not been described to date. The vast majority of bis(pyridine) complexes of $\mathrm{Zn}$ (II) halides adopt simple mononuclear tetrahedral geometries [69]. The reaction products of $\mathrm{ZnCl}_{2}$ with 3,5-dichloropyridine, 3,5-dibromopyridine [69] and 2-chloropyrazine [74] represent the only examples for which onedimensional polymeric structures have been confirmed. We note that the chemically related derivative of zincdichloride with 2,6dichloropyrazine does not crystallize as a chain polymer but rather exhibits the mononuclear tetrahedral structure [75]. The same is true for the complex of $\mathrm{ZnCl}_{2}$ with unsubstituted pyridine: This structure has been determined independently by several groups; priority goes to Zannetti and Serra [76]. The fact that only halogen-substituted pyridine ligands are compatible with the chain structure type in the case of the small $\mathrm{Zn}$ (II) center suggests a kind of specific stabilization for these derivatives. Obvious possibilities for such a stabilization include attractive halogen $\cdots$ halogen interactions along the polymer strand as well as nonclassical hydrogen bonds [69]. A detailed study of these secondary interactions based on high resolution X-ray diffraction experiments followed by the topological analysis of the experimental electron density has very recently been completed [77]. In addition to the above-mentioned chain polymers, a small number of structurally related 2D networks involving octahedrally 
coordinated $\mathrm{Zn}(\mathrm{II})$ and crosslinking ditopic ligands is known; these compounds will be discussed in section 3.2. In sharp contrast to these findings for the derivatives of the small $\mathrm{Zn}(\mathrm{II})$, chain polymers are very popular for the higher homologue Cd(II). In the case of this much larger cation, mononuclear tetrahedral complexes must be considered the exception to the rule and are restricted to the heaviest halide iodide [78].

Table 1 summarizes the results obtained on 16 structurally characterized $\left[\mathrm{M}(\mu-\mathrm{X})_{2} \mathrm{py}_{2}\right]_{\infty}$ polymers with 3,5-disubstituted pyridine derivatives. They share a common feature with the early structural studies cited above: The intermetal distance in chain direction corresponds to the shortest lattice parameter, typically between 3.6 and 4.1 Å. Ten of the compounds listed in Table 1, among them two of the rather rare $\mathrm{Zn}$ (II) polymers, are isomorphous and crystallize in the non-centrosymmetric tetragonal space group $P-4 b 2$ (no. 117). This structure type is associated with very effficient space filling and hence popular among the chain polymers of suitable symmetry although $P-4 b 2$ does not represent a common space group in general, with only 31 occurences in the Cambridge Structural Database [16]. $P-4 b 2$ is a highly symmetric space group, and all metal-halide bonds have the same length; Fig. 8 shows a chain in $\left[\mathrm{Hg}(\mu-\mathrm{Cl})_{2}(3,5 \text {-dibromopy })_{2}\right]_{\infty}$ as an example. Despite its similar chemical composition, the analogous $\left[\mathrm{Hg}(\mu-\mathrm{Br})_{2}(3,5 \text {-dibromopy })_{2}\right]_{\infty}$ (Fig. 9) crystallizes in space group $P-1$ with much less symmetry restrictions [40]. This solid features significantly different $\mathrm{Hg}-\mathrm{Br}$ distances in the polymer backbone, and its geometry may be conceived as sequence of $\mathrm{HgBr}_{2}$ units aggregated via considerably longer and weaker $\mathrm{Hg} \cdots \mathrm{Br}$ interactions. The situation is depicted in Scheme 2.

Table 1: $\left[\mathrm{M}(\mu-\mathrm{X})_{2} \mathrm{py}_{2}\right]_{\infty}$ chain polymers of 3,5-disubstituted pyridines.

$\begin{array}{cccccc}\mathrm{M} & \mathrm{X} & \text { ligand py } & \text { intrachain } \mathrm{M} \cdots \mathrm{M}[\AA] & \text { space group } & \text { reference } \\ & & & & & \\ \mathrm{Mn} & \mathrm{Br} & \text { 3,5-dimethylpyridine } & 3.930(3) & P b a m & {[79]} \\ \mathrm{Cu} & \mathrm{Br} & \text { 3,5-dimethylpyridine } & 4.097(1) & P 21 / a & {[80]} \\ \mathrm{Zn} & \mathrm{Cl} & \text { 3,5-dichloropyridine } & 3.6542(10) & P-4 b 2 & {[69]} \\ \mathrm{Zn} & \mathrm{Cl} & \text { 3,5-dibromopyridine } & 3.7300(12) & P-4 b 2 & {[69]} \\ \mathrm{Cd} & \mathrm{Cl} & \text { 3,5-dichloropyridine } & 3.7707(4) & P-4 b 2 & {[78]} \\ \mathrm{Cd} & \mathrm{Cl} & \text { 3,5-dibromopyridine } & 3.8543(4) & P-4 b 2 & {[78]} \\ \mathrm{Cd} & \mathrm{Cl} & \text { 3,5-dimethylpyridine } & 3.8790(4) & P-4 b 2 & {[78]} \\ \mathrm{Cd} & \mathrm{Br} & \text { 3,5-dichloropyridine } & 3.8838(11) & C 2 / m & {[78]} \\ \mathrm{Cd} & \mathrm{Br} & \text { 3,5-dibromopyridine } & 3.9267(8) & P-4 b 2 & {[78]} \\ \mathrm{Cd} & \mathrm{Br} & \text { 3,5-dimethylpyridine } & 3.9776(4) & P-4 b 2 & {[78]} \\ \mathrm{Cd} & \mathrm{I} & \text { 3,5-dichloropyridine } & 4.1398(5) & I 4{ }_{1} m d & {[78]} \\ \mathrm{Cd} & \mathrm{I} & \text { 3,5-dibromopyridine } & 4.1428(6) & C 2 / m & {[78]} \\ \mathrm{Hg} & \mathrm{Cl} & \text { 3,5-dichloropyridine } & 3.8148(7) & P-4 b 2 & {[40]} \\ \mathrm{Hg} & \mathrm{Cl} & \text { 3,5-dibromopyridine } & 3.8871(8) & P-4 b 2 & {[40]} \\ \mathrm{Hg} & \mathrm{Cl} & \text { 3,5-dimethylpyridine } & 3.9721(3) & P-4 b 2 & {[40]} \\ \mathrm{Hg} & \mathrm{Br} & \text { 3,5-dibromopyridine } & 4.0004(11) & P-1 & {[40]}\end{array}$

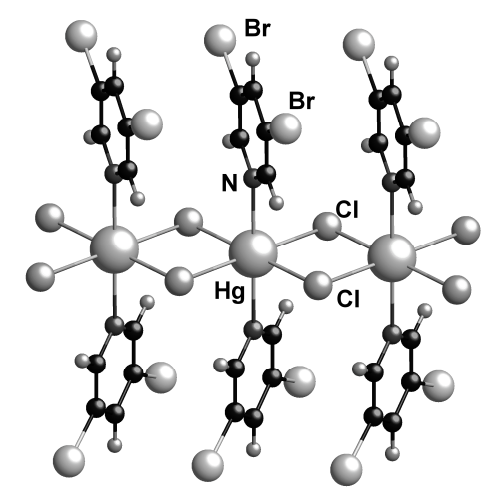

Fig. 8. Chain in $\left[\mathrm{Hg}(\mu-\mathrm{Cl})_{2}(3,5 \text {-dibromopy })_{2}\right]_{\infty}$. All Hg-Cl distances amount to 2.6707(15) $\AA$. Structural result from ref [40]. 


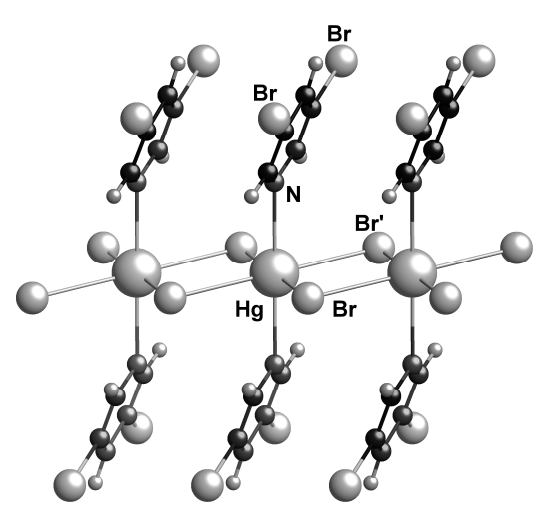

Fig. 9. One of two symmetrically independent but similar chains in $\left[\mathrm{Hg}(\mu-\mathrm{Br})_{2}(3,5 \text {-dibromopy })_{2}\right]_{\infty}$ with asymmetric metalbromide-metal bridges. Interatomic distances [values for the second molecule in square brackets]: $\mathrm{Hg}-\mathrm{Br}=2.5033(16) \AA$

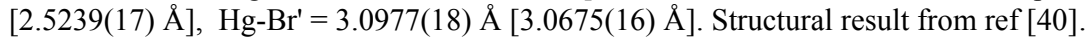

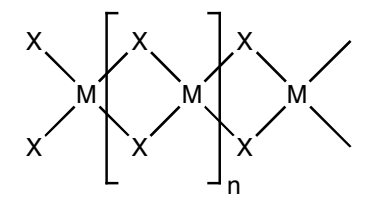

a

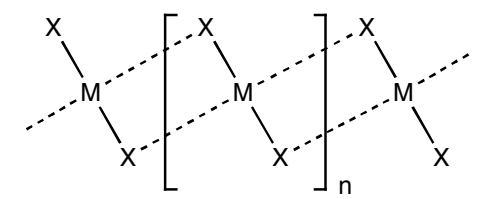

b

Scheme 2. Protoype $\left[\mathrm{M}(\mu-\mathrm{X})_{2}\right]_{\infty}$ backbones in $\left[\mathrm{M}(\mu-\mathrm{X})_{2}(\mathrm{py})_{2}\right]_{\infty}$ (py = 3,5-disubstituted pyridine); a) Symmetric metal-halide binding as encountered in solids crystallizing in $P-4 b 2$, e.g. in $\left[\mathrm{Hg}(\mu-\mathrm{Cl})_{2}(3,5 \text {-dibromopy })_{2}\right]_{\infty}\left(c f\right.$. Fig. 8) b). Preformed $\mathrm{MX}_{2}$ subunits e.g. in $\left[\mathrm{Hg}(\mu \text {-Br })_{2}(3,5 \text {-dibromopy })_{2}\right]_{\infty}$ (cf. Fig. 9).

A straightforward relationship exists between the one-dimensional $\left[\mathrm{M}(\mu-\mathrm{X})_{2}(\mathrm{py})_{2}\right]_{\infty}$ structures and their popular twodimensional congeners in which each of the heteroaromatic rings in $4,4^{\prime}$-bipyridine stands for a pyridine ligand in adjacent $[\mathrm{M}(\mu$ $\left.\mathrm{X})_{2}(\text { py })_{2}\right]_{\infty}$ strands. The resulting crosslinked polymers will be covered in section 3.2.

The donor ligand is not restricted to pyridine derivatives attached via nitrogen; we have been able to characterize the chain polymer $\left[\mathrm{Cd}(\mu-\mathrm{Cl})_{2}\left(\mathrm{C}_{5} \mathrm{H}_{5} \mathrm{NO}\right)\left(\mathrm{H}_{2} \mathrm{O}\right)\right]$ with pyridine- $N$-oxide and aqua donor ligands [81]. This compound is shown in Fig. 10: The syndiotactic orientation of the different apical ligands results in a repeat unit along the chain twice as long as the intermetal distance.

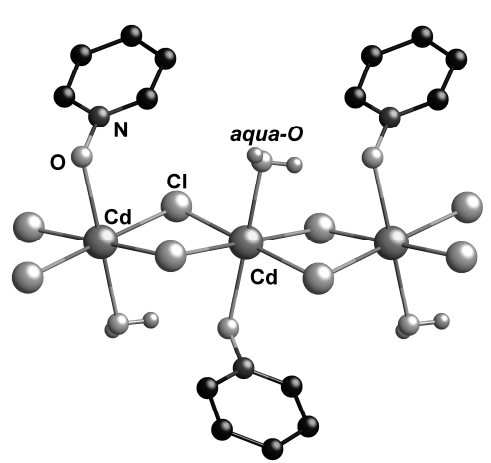

Fig. 10. $\left[\mathrm{Cd}(\mu-\mathrm{Cl})_{2}\left(\mathrm{C}_{5} \mathrm{H}_{5} \mathrm{NO}\right)\left(\mathrm{H}_{2} \mathrm{O}\right)\right]_{\infty}$ chain; structural result from ref $[81]$.

The two donor ligands in the polymers discussed above occupy axial trans positions in a distorted octahedron; the resulting chains are linear. If the bridging halide ligands responsible for edge-sharing of adjacent octahedra are not arranged in a coplanar fashion, the donor ligands rather adopt a cis geometry as shown in Scheme 1h: A zig-zag rather than a linear chain is formed. Chelating ligands binding to $c i s$ sites in the coordination octahedron around the divalent cation can obviously enforce this geometry. The 2,2'-bipyridine complexes [ $\mathrm{MX}_{2}$ (2,2'-bipy)], $\mathrm{M}=\mathrm{Mn}, \mathrm{X}=\mathrm{Cl}$ [82], $\mathrm{M}=\mathrm{Cd}, \mathrm{X}=\mathrm{Br}$ [83, 84], $\mathrm{M}=\mathrm{Pb}, \mathrm{X}=\mathrm{Br}$ [85], $\mathrm{M}=\mathrm{Cu}, \mathrm{X}=\mathrm{Br}[86]$ represent a series of isomorphous compounds, all crystallizing in space group $C 2 / c$ with similar lattice parameters. Fig. 11 shows a zig-zag chain in $\left[\mathrm{CdBr}_{2}\left(2,2^{\prime}\right.\right.$-bipy $\left.)\right][83,84]$. This family also comprises the not strictly isomorphous but chemically related compounds $\left[\mathrm{CuCl}_{2}\left(2,2^{\prime}\right.\right.$-bipy)] [86], [ $\mathrm{CuBr}_{2}(4,4$ '-dimethyl-2,2'-bipy)] [87, 88], and the phenanthroline derivatives $\left[\mathrm{CdI}_{2}(1,10\right.$-phen) $][89]$ and $\left[\mathrm{FeCl}_{2}(1,10\right.$-phen $\left.)\right][90]$. 


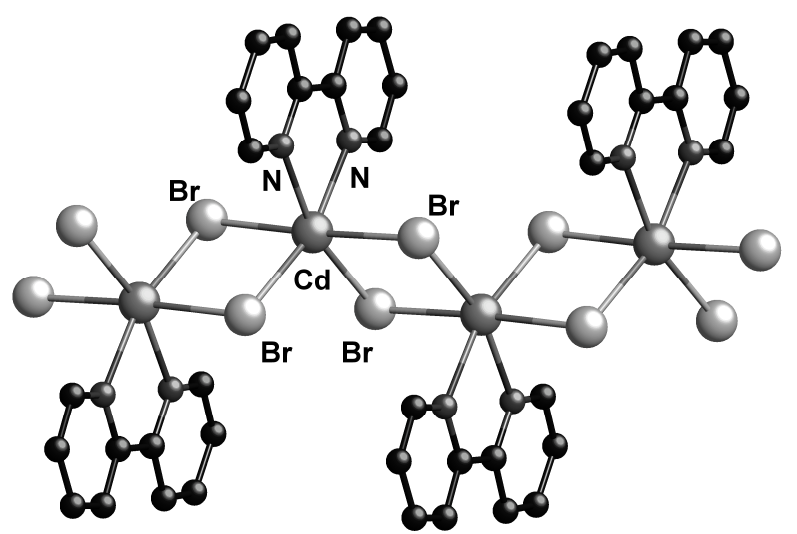

Fig. 11. Edge-sharing of octahedra with cis geometry in $\left[\mathrm{Cd}(\mu-\mathrm{Br})_{2}\left(2,2^{\prime}-\text { bipy }\right)\right]_{\infty}$; structural result from ref [83].

Usually the heavier halides, i.e. chloride, bromide or iodide, act as bridging ligands in $\left[\mathrm{M}^{\mathrm{II}}(\mu-\mathrm{X})_{2} \mathrm{~L}_{2}\right]_{\infty}$ polymers whereas the smaller congener fluoride is rarely encountered in this role. An exception is the pyrazole derivative shown in Fig. 12; according to its authors, this polymer owes its existence to strong $\mathrm{N}-\mathrm{H} \cdots \mathrm{F}$ hydrogen bonds $[91,92]$ with donor $\cdots$ acceptor distances $\mathrm{N} \cdots \mathrm{F}$ of ca. $2.7 \AA$.

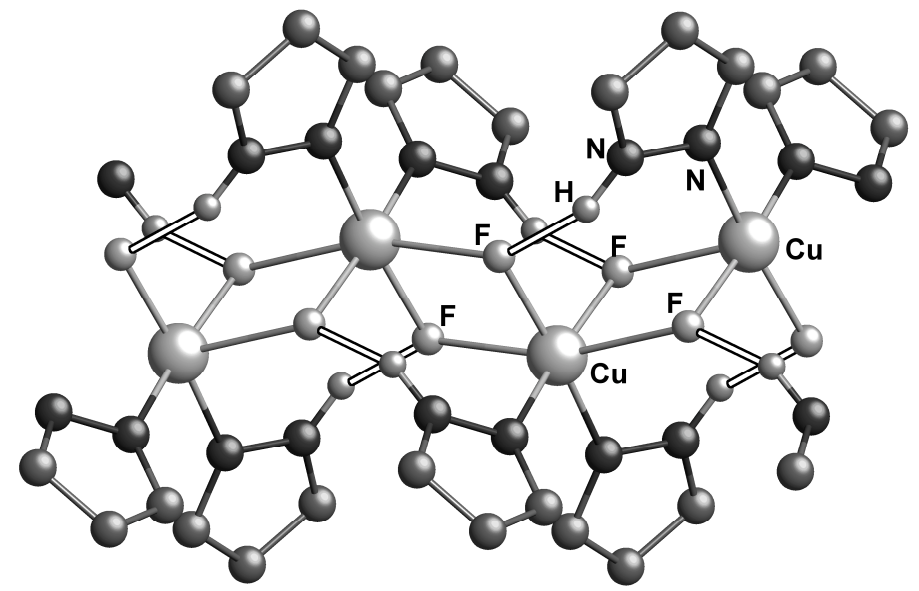

Fig. 12. Edge-sharing of octahedra with cis geometry in $\left[\mathrm{Cu}(\mu-\mathrm{F})_{2} \mathrm{~L}_{2}\right]_{\infty}(\mathrm{L}=3$-methyl-4-ethyl-5-phenylpyrazole); for clarity, only the pyrazole fragment of the ligand is shown, $\mathrm{H} \cdots \mathrm{F}$ interactions are drawn as open bonds. Structural result from ref [92].

Alternating trans (Scheme 1g) and cis (Scheme 1h) configurations of the two donor ligands per metal center may also be encountered within the same polymer chain. As an example for a chain polymer with such a mixed cis and trans configuration $\left.\left[\mathrm{Cu}_{2} \mathrm{Cl}_{4} \text { (trans-chd)(thf }\right)_{2}\right][93]$ is shown in Fig. 13.

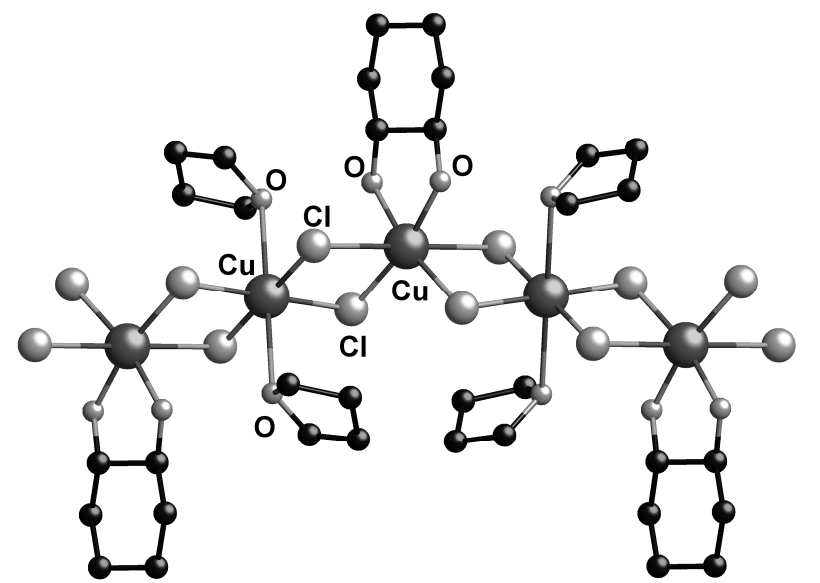

Fig. 13. Alternating cis and trans geometry in $\left.\left[\mathrm{Cu}_{2} \mathrm{Cl}_{4} \text { (trans-chd)(thf) }\right)_{2}\right]$; structural result from ref [93].

A similar arrangement of two monodentate donor ligands attached in trans octahedral and a chelating ligand bonded in cis octahedral fashion to neighbouring Cd cations along the polymer chain was described by Wei et al. [94] for 
$\left[\mathrm{Cd}_{3} \mathrm{Cl}_{6}(\mathrm{NIToPy})_{2}(\mathrm{thf})_{2}\right]$. In this compound, however, a composition with one trans configured Cd versus two cis configured complexes is encountered. Remarkably, the diamagnetic $\mathrm{Cd}(\mathrm{II})$ ions contribute to weak antiferromagnetic coupling between the paramagnetic NIToPy ligands in chain direction. More complex chains constructed from different polyhedra are covered in Section 2.7 if all metal centers interact with donor ligands or in Section 4.2 if metal halide fragments without donor ligands are incorporated in the polymers.

In both connectivity patterns described above, all halogen ligands act as bridges between neighbouring metal cations. An alternative for constructing chain polymers via edge-sharing is depicted in Scheme 1i: Three of the halide ligands pertain to two shared edges in adjacent polyhedra, thus acting as bridge between three metals, whereas a forth halide serves as terminal ligand. The 1,3-diaminopropane derivatives $\left[\mathrm{Cd}\left(\mu_{3}-\mathrm{Cl}\right) \mathrm{Cl}(\mathrm{dap})\right]_{\infty}[95]$ and $\left[\mathrm{Cd}\left(\mu_{3}-\mathrm{Br}\right) \mathrm{Br}(\mathrm{dmpd})\right]_{\infty}[96]$ are examples for this structure type. A section of the polymer chain of the latter compound is represented in Fig. 14. In agreement with the expectation, the bond distances between the metal cations and the triply bridging bromide (ca. 3.0 A) are significantly longer than the terminal $\mathrm{Cd}-\mathrm{Br}$ bonds (ca. $2.6 \AA$ ).

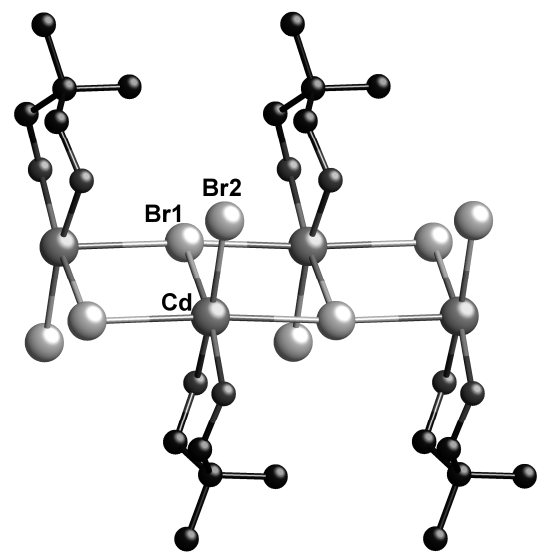

Fig. 14. Chain in $\left[\mathrm{Cd}\left(\mu_{3}-\mathrm{Br}\right) \mathrm{Br}(\mathrm{dmpd})\right]_{\infty}$. Cd-Br1 $=3.005 \AA, \mathrm{Cd}-\mathrm{Br} 2=2.583 \AA$. Structural result from ref [96].

\subsection{Chains from face-sharing octahedra}

In agreement with Pauling's rules [97] face-sharing of adjacent octahedra is in general less popular than edge- or cornersharing. Face-sharing in chain polymers of divalent metals is accomplished in the classical inorganic compound $\mathrm{CsCuCl}_{3}$. $\mathrm{The}$ crystal structure of this "hexagonal perovskite" was finally elucidated by Schlueter, Jacobsen and Rundle [98]. With respect to the focus of this review, a similar connectivity is encountered if two halides and a donor ligand bridge neighbouring cations as shown in Scheme 1j. Fig. 15 shows the section of a polymer chain in $\left[\mathrm{Cd}(\mu-\mathrm{Cl})_{2}(\mu-4-1 \mathrm{H}-\text { pyridone- } O, O)\right]_{\infty}[99]$. The distance between neighbouring Cd(II) cations amounts to only 3.3404(10) $\AA$, to be compared with ca. $3.8 \AA$ in the edge-sharing polymers compiled in Table 1 and to 5.1230(8) in the corner-sharing $\left[\mathrm{Cd}_{2}(\mu-\mathrm{Cl})_{4}(\mathrm{hmt})\left(\mathrm{CH}_{3} \mathrm{OH}\right)_{2}\right]_{\infty}[100]$.

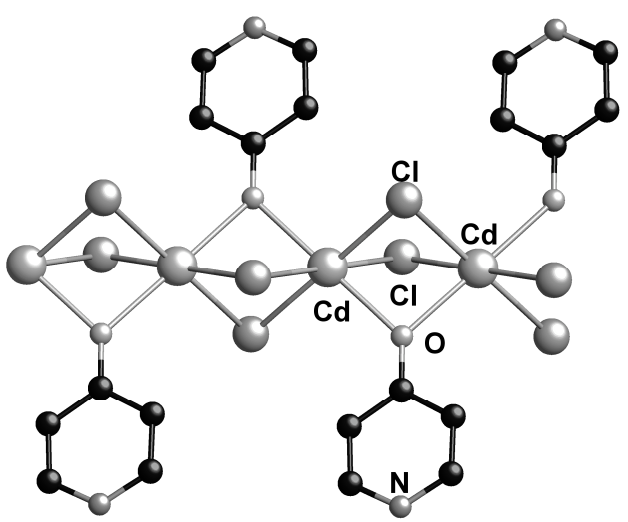

Fig. 15. Face-sharing in $\left[\mathrm{Cd}(\mu-\mathrm{Cl})_{2}(\mu-4-1 \mathrm{H}-\text { pyridone- } O, O)\right]_{\infty}$. Structural result from ref [99].

"Almost" face-sharing connectivities are encountered when in addition to the two halides per face (Scheme 1j) a larger molecular fragment rather than a single atom of a donor ligand acts as the third bridging moiety. Two vicinal nitrogen atoms of the heterocyclic ligands pyridazine [101, 102], 4-amino-3-methyl-1,2,4-triazole [103], 1,2,4-triazolato [104] or tetrazol [105] may play that role as well as an O,O'-carboxylato group [106-109]. Straightforward distance criteria underline the efficiency of a vicinal diatomic bridge such as pyridazine: The closest intermetal $\mathrm{Hg} \cdots \mathrm{Hg}$ distances along chloride-bridged polymer chains amount to $5.01 \AA$ in the case of corner-sharing [110], to ca. $3.9 \AA$ for edge-sharing, $c f$. Table 1, and to $3.58 \AA$ in the "almost" facesharing pyridazine complex [101], reflecting the same trend as the $\mathrm{Cd}(\mathrm{II})$ polymers mentioned above. 
Examples for face-sharing octahedra with very "dilute" donor ligands are discussed in section 4.1.

\subsection{Chains from polyhedra with coordination number greater than 6}

Only a few examples of coordination polymers based on halide bridged divalent metal cations with coordination number 7 have been described, and no structural results on higher coordination numbers have been reported with respect to the target compounds of this review.

The quinquedentate macrocycle N,N'-(3,7-diazanonane-1,9-diyl)-2,6-diacetiminopyridine occupies the equatorial positions in a pentagonal bipyramide around $\mathrm{Cd}(\mathrm{II})$; axial bromo ligands bridge the metal centers to infinite cationic chains in the ionic compound $[\mathrm{Cd}(\mu-\mathrm{Br}) \text { macrocycle }]_{2} \mathrm{CdBr}_{4}[111]$.

Four bridging chloro ligands and one planar tridentate $N$ donor $\mathrm{H}_{2}$ dapd coordinate to each $\mathrm{Mn}(\mathrm{II})$ in $\left[\mathrm{Mn}(\mu-\mathrm{Cl})_{2}\left(\mathrm{H}_{2} \mathrm{dapd}\right)\right]_{\infty}$; the resulting pentagonal bipyramids are linked via shared edges to chains (Fig. 16) [112, 113].

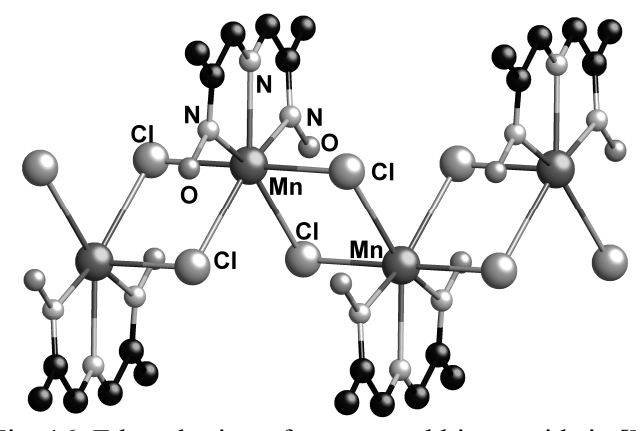

Fig. 16. Edge-sharing of pentagonal bipyramids in $\left[\mathrm{Mn}(\mu-\mathrm{Cl})_{2}\left(\mathrm{H}_{2} \text { dapd }\right)\right]_{\infty}$. Structural result from ref [112].

\subsection{Chains incorporating different types of polyhedra}

The chain polymers discussed in the previous chapters were based on repetition of only one type of polyhedron as the repeat unit. In addition to these prototypic cases shown in Scheme 1, chains incorporating different subunits may be encountered. These more complex polymers are covered in this section.

Pseudo-octahedral and square-pyramidal $\mathrm{Ni}(\mathrm{II})$ coordination alternate in chain direction in the bromide-bridged polymer $\left[\left\{\mathrm{Ni}(\mu-\mathrm{Br})_{2}(\mathrm{thf})_{2}\right\}_{2}\left\{\mathrm{Ni}(\mu-\mathrm{Br})_{2}(\mathrm{thf})\right\}\right]$; due to the kinks in the square-pyramidal moieties, a slightly undulated chain results [114].

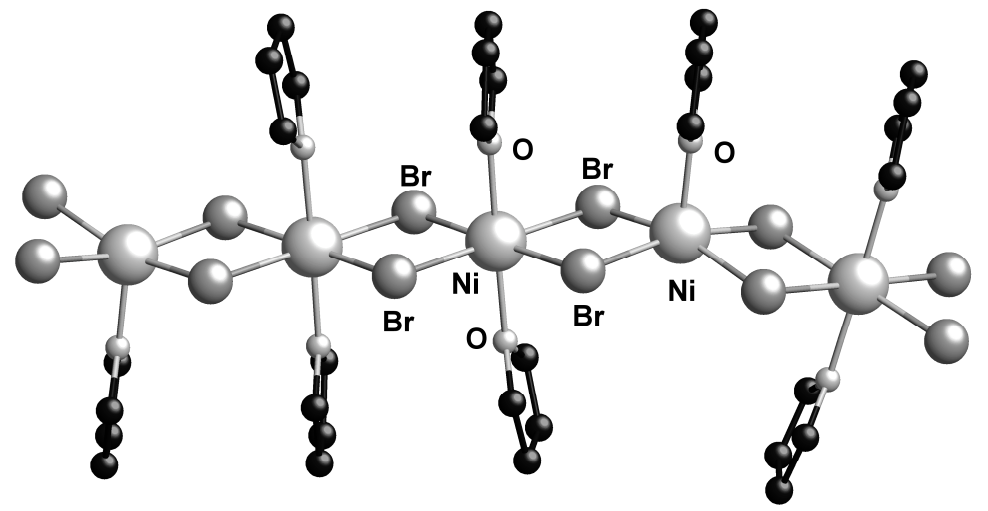

Fig. 17. Sequence of two octahedral and one square-pyramidal building blocks in $\left[\left\{\mathrm{Ni}(\mu-\mathrm{Br})_{2}(\operatorname{thf})_{2}\right\}_{2}\left\{\mathrm{Ni}(\mu-\mathrm{Br})_{2}(\mathrm{thf})\right\}\right]_{\infty}$. Structural result from ref [114].

A rather complex connectivity pattern is encountered in the chain polymer of formal composition $\left[\mathrm{Mn}_{5} \mathrm{Cl}_{10}(\mathrm{EtOH})_{14}\right][115]$. Three different types of octahedra around divalent Mn cations occur: Chain fragments of three corner-sharing octahedra link pairs of edge-sharing octahedra, see Fig. 18. The overall sequence is stabilized by $\mathrm{O}-\mathrm{H} \cdots \mathrm{Cl}$ hydrogen bonds. 


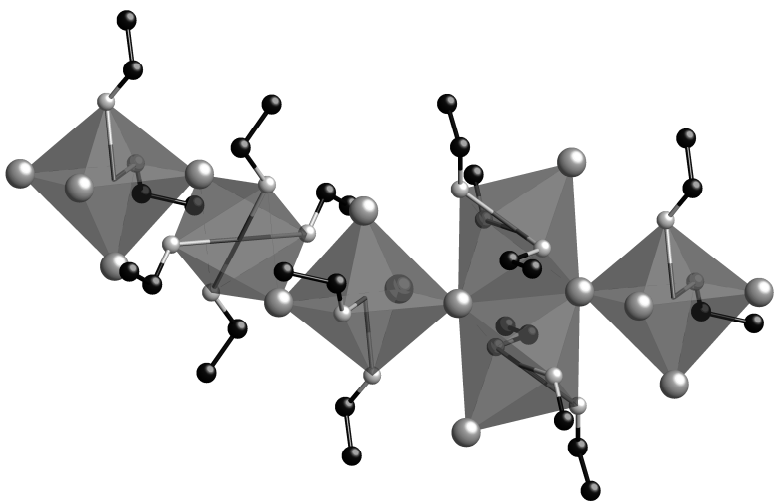

Fig. 18. Linkage of octahedra in $\left[\mathrm{Mn}_{5} \mathrm{Cl}_{10}(\mathrm{EtOH})_{14}\right]$. Structural result from ref [115].

As mentioned in the Introduction, connectivity criteria may be ambiguous: With standard bond distances in mind, the polycationic chain in the compound catena-[bis( $\mu$-bromo)hexaaquadicopper(II)] bis[( $\mu$-bromo)-(pyridine-2,6-

dicarboxylato)cuprate(II)] [116] shown in Fig. 19 will be interpreted as an alternating sequence of distorted octahedral and square planar $\mathrm{Cu}$ (II) Jahn-Teller cations. The four-coordinated $\mathrm{Cu}$ (II), however, is only $3.18 \AA$ away from a bromide in the counteranion, and this admittedly rather distant additional ligand would complete an elongated octahedral coordination polyhedron for the second copper cation, too.

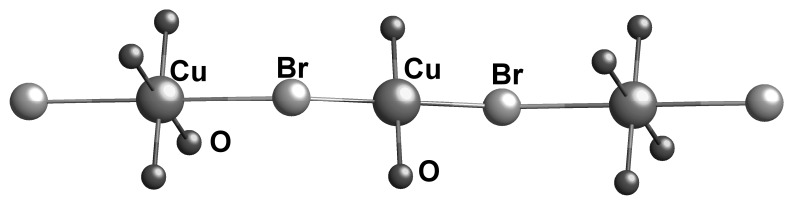

Fig. 19. Section of a cationic $\left[\left\{\mathrm{Cu}\left(\mathrm{OH}_{2}\right)_{2}(\mu-\mathrm{Br}) \mathrm{Cu}\left(\mathrm{OH}_{2}\right)_{4}(\mu-\mathrm{Br})\right\}^{2+}\right]$ chain. Structural result from ref [116].

\section{Polymers with additional crosslinking}

Additional crosslinks between halide-bridged chains result in the formation of higher dimensional extended solids. We will distinguish two alternatives: The first corresponds to the structure type depicted in Scheme 3a with halide bridges in two dimensions and will de discussed in section 3.1. These compounds as well as the chain polymers treated in the preceding section are often addressed as organic-inorganic hybrid materials rather than as coordination polymers. An often-quoted definition of the latter class of compounds requires the presence of an organic group in at least one extended dimension [117]. The polymers cross-linked by ditopic donor ligands according to the popular connectivity shown in Scheme $3 \mathrm{~b}$ belong to this category; they will be covered in section 3.2

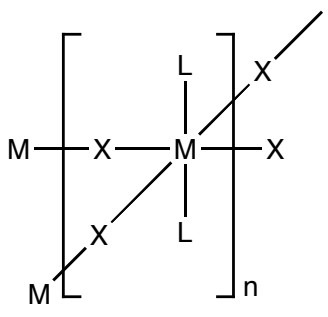

a

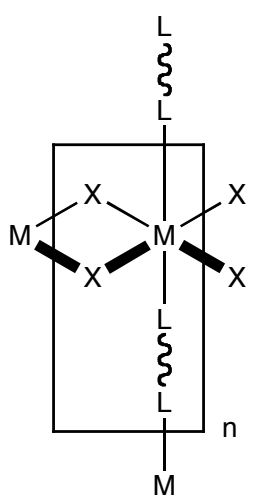

b

Scheme 3. Protoype geometries for crosslinked polymers; $\mathrm{M}=$ divalent metal, $\mathrm{X}=$ halogen, $\mathrm{L}=$ donor ligand, $\mathrm{L}-\mathrm{L}=$ bridging donor ligand. a) Two-dimensional halide-bridged arrangement, covered in section 3.1; b) Halide-bridging in one and donor-ligand bridging in a second dimension, covered in section 3.2. 


\subsection{Polymers with halide bridges in two dimensions}

The binary halide $\mathrm{NbF}_{4}$ [118] matches the topology illustrated in Scheme 3a: In agreement with the more instructive formula $\left[\mathrm{MX}_{2} \mathrm{X}_{4 / 2}\right]_{\infty}^{2}$, four halides in the equatorial plane of a pseudo-octahedron act as bridges to neighbouring cations whereas the apical positions are occupied by terminal ligands. If these terminal ligands are organic donors rather than halide anions, neutral twodimensional polymers of divalent metals, the protagonists of this section, are obtained.

Structural studies have been devoted to solids with this type of connectivity containing divalent copper, cobalt and mercury. A series of isomorphous compounds with the composition [M( $\left.\mu-\mathrm{X})_{2}(1-\mathrm{R}-1 H \text {-tetrazole })_{2}\right]$ is known for $\mathrm{M}=\mathrm{Co}, \mathrm{X}=\mathrm{Cl}[119], \mathrm{M}$ $=\mathrm{Cu}, \mathrm{X}=\mathrm{Cl}[120-122],[123,124]$ and $\mathrm{M}=\mathrm{Cu}, \mathrm{X}=\mathrm{Br}[14,125,126]$. The solids contain metal halide layers which extend along [010] and [001], and the structures are remarkably conservative with respect to the relevant lattice parameters: Despite the different cations and halides, the unit cell dimensions $b$ and $c$ only range from 6.727 to $6.970 \AA$ and from 7.000 to $7.702 \AA$. In contrast, the different 1-substituted tetrazole ligands protrude in the direction of the crystallographic $a$ axis which varies between 11.032 and $15.616 \AA$. Even in $\left[\mathrm{Hg}(\mu-\mathrm{I})_{2}(8 \text {-aad })_{2}\right][110]$ with the purine ligand 8-azaadenine essentially the same intralayer dimensions are conserved. As an example for this structure type the network $\left[\mathrm{Cu}(\mu-\mathrm{Br})_{2}(1 \text {-methyl- } 1 H \text {-tetrazol })_{2}\right]$ is shown in Fig. 20 .

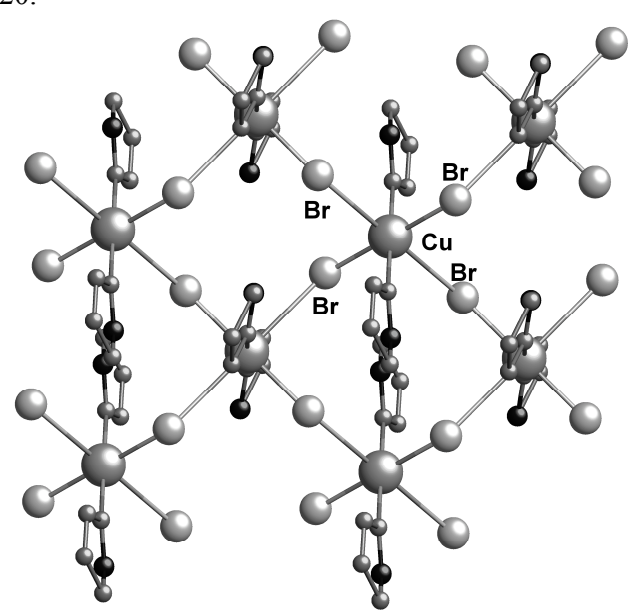

Fig. 20. View on a layer of the two-dimensional network $\left[\mathrm{Cu}(\mu \text {-Br })_{2}(1 \text {-methyl- } 1 H \text {-tetrazol })_{2}\right]$; the methyl substituents on the tetrazole ligands above and below the metal halide network have been omitted for clarity. Structural result from ref [14].

These tetrazole derivatives organize potential spin centers in square polymeric grids; the interlayer interactions are orders of magnitude weaker. The three-dimensional solids may therefore be considered good models for two-dimensional magnetic interactions $[125,126]$.

Bell et al. characterized the ligand-deficient complex $\left[\mathrm{Hg}(\mu-\mathrm{I})_{2}\left(\mathrm{PMe}_{3}\right)_{2}\left\{\mathrm{Hg}(\mu-\mathrm{I})_{2}\right\}_{2}\right][127]$ which might also be included in section 4.3. In this compound $\mathrm{Hg}(\mathrm{II})$ cations adopt two distinctly different coordination environments, namely a distorted octahedron and a strongly distorted tetrahedron (Fig. 21).

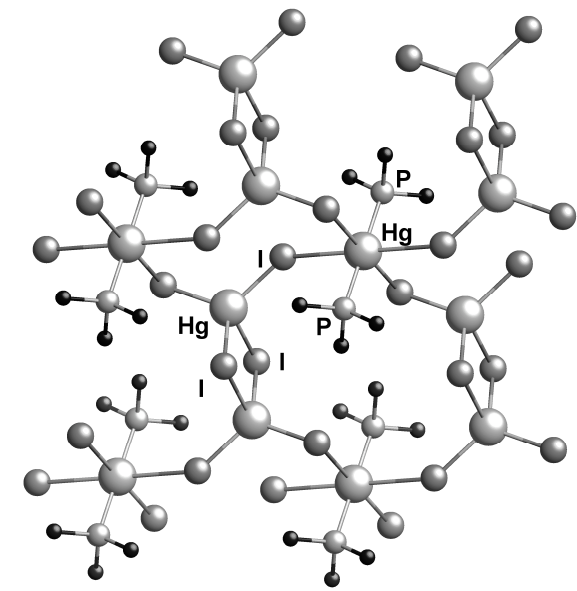

Fig. 21. View on a layer of the two-dimensional network $\left[\mathrm{Hg}(\mu-\mathrm{I})_{2}\left(\mathrm{PMe}_{3}\right)_{2}\left\{\mathrm{Hg}(\mu-\mathrm{I})_{2}\right\}_{2}\right]$. Structural result from ref [127]. 


\subsection{Polymers with crosslinking donor ligands}

In this section, extended solids with halide bridges in one and bridging donor ligands in a second dimension will be discussed. Special emphasis will be on the topology shown in Scheme 3b. Ditopic $N$ donors prevail, but examples for other ligand types have also been described.

We will first focus on the popular ligand 4,4'-bipyridine as linker. Compounds with the stoichiometry $\left[\mathrm{M}(\mu-\mathrm{X})_{2}\left(4,4^{\prime}\right.\right.$-bipy)] have been described for divalent cations as small as $\mathrm{Ni}$ (II) or $\mathrm{Zn}$ (II) and as large and soft as $\mathrm{Pb}$ (II) or $\mathrm{Hg}$ (II), with all halides but fluoride. Table 2 gives an overview of the structurally characterized compounds.

Table 2: $\left[\mathrm{M}(\mu-\mathrm{X})_{2}\left(4,4^{\prime}-\right.\right.$-bipy $\left.)\right] 2 \mathrm{D}$ polymers.

\begin{tabular}{|c|c|c|c|c|c|}
\hline M & $\mathrm{X}$ & $\begin{array}{l}\text { halide-bridged } \\
\text { M } \cdots \mathrm{M}[\AA]\end{array}$ & $\begin{array}{c}\text { reported } \\
\text { space group }\end{array}$ & reference & comment \\
\hline Mn & $\mathrm{Cl}$ & $3.6780(10)$ & Pban & [128] & see text for space group \\
\hline $\mathrm{Fe}$ & $\mathrm{Cl}$ & $3.6380(10)$ & $\mathrm{Cmmm}$ & [129] & \\
\hline Co & $\mathrm{Cl}$ & $3.6110(10)$ & $\mathrm{Cmmm}$ & [129] & \\
\hline $\mathrm{Ni}$ & $\mathrm{Cl}$ & $3.5830(3)$ & $\mathrm{Cmmm}$ & {$[15]$} & from powder data \\
\hline $\mathrm{Ni}$ & $\mathrm{Br}$ & $3.7338(1)$ & $\mathrm{Cmmm}$ & {$[15]$} & from powder data \\
\hline $\mathrm{Zn}$ & $\mathrm{Cl}$ & $3.6199(6)$ & Pban & [130] & at $120 \mathrm{~K}$ - see text for high temperature phase \\
\hline $\mathrm{Zn}$ & $\mathrm{Cl}$ & $3.6433(7)$ & Pban & [130] & at $293 \mathrm{~K}$ - see text for high temperature phase \\
\hline $\mathrm{Cd}$ & $\mathrm{Cl}$ & $3.7716(10)$ & Pban & [131] & at $120 \mathrm{~K}$ \\
\hline $\mathrm{Cd}$ & $\mathrm{Cl}$ & $3.7748(16)$ & Pban & [131] & at $293 \mathrm{~K}$ \\
\hline $\mathrm{Cd}$ & $\mathrm{Cl}$ & $3.7959(9)$ & Pban & [131] & at $450 \mathrm{~K}$ \\
\hline $\mathrm{Cd}$ & $\mathrm{Cl}$ & $3.781(2)$ & $\mathrm{Cmmm}$ & [132] & at $293 \mathrm{~K}$ - see text for space group \\
\hline $\mathrm{Cd}$ & $\mathrm{Br}$ & $3.8851(5)$ & Pban & [131] & at $120 \mathrm{~K}$ \\
\hline $\mathrm{Cd}$ & $\mathrm{Br}$ & $3.9105(3)$ & Pban & [131] & at $293 \mathrm{~K}$ \\
\hline $\mathrm{Cd}$ & $\mathrm{Br}$ & $3.9242(10)$ & $\mathrm{Cmmm}$ & [133] & at $293 \mathrm{~K}$ - see text for space group \\
\hline $\mathrm{Cd}$ & I & 4.1423(4) & $\mathrm{Cmmm}$ & [131] & at $120 \mathrm{~K}$ \\
\hline $\mathrm{Cd}$ & I & $4.1550(9)$ & $\mathrm{Cmmm}$ & [131] & at $150 \mathrm{~K}$ \\
\hline $\mathrm{Cd}$ & I & $4.166(1)$ & $\mathrm{Cmmm}$ & [134] & at $193 \mathrm{~K}$ \\
\hline $\mathrm{Cd}$ & I & $4.1751(4)$ & $\mathrm{Cmmm}$ & [131] & at $293 \mathrm{~K}$ \\
\hline $\mathrm{Cd}$ & I & $4.1515(9)$ & $\mathrm{Cmmm}$ & {$[135]$} & at $293 \mathrm{~K}$ \\
\hline $\mathrm{Hg}$ & $\mathrm{Cl}$ & $3.8538(7)$ & $\mathrm{Cmmm}$ & [136] & \\
\hline $\mathrm{Hg}$ & $\mathrm{Br}$ & $3.9450(13)$ & $\mathrm{Cmmm}$ & [137] & \\
\hline $\mathrm{Pb}$ & $\mathrm{Cl}$ & $3.9490(13)$ & $P-1$ & [138] & at $200 \mathrm{~K}$ - see text for phase transition \\
\hline $\mathrm{Pb}$ & $\mathrm{Cl}$ & $3.9813(3)$ & $P-1$ & [139] & at $294 \mathrm{~K}$, hydrothermal \\
\hline $\mathrm{Pb}$ & $\mathrm{Cl}$ & $4.1107(3)$ & $C 2 / m$ & [138] & at $293 \mathrm{~K}$ - see text for phase transition \\
\hline $\mathrm{Pb}$ & $\mathrm{Cl}$ & $4.0991(7)$ & $\mathrm{Cmmm}$ & [138] & at $450 \mathrm{~K}$ - see text for phase transition \\
\hline $\mathrm{Pb}$ & $\mathrm{Br}$ & 4.2191(10) & $C 2 / m$ & [140] & \\
\hline $\mathrm{Pb}$ & $\mathrm{Br}$ & $4.217(3)$ & $C 2$ & [141] & \\
\hline $\mathrm{Pb}$ & I & $4.4410(11)$ & $C 2 / m$ & [142] & \\
\hline
\end{tabular}

Crystal symmetry in this class of solids merits a closer inspection. Many of the compounds have been described in space group Cmmm. In 1991, Chippindale and coworkers published the crystal structure of [ $\mathrm{Mn}(\mu-\mathrm{Cl})_{2}\left(4,44^{\prime}-\right.$ bipy $\left.)\right][128]$ and carefully addressed this issue. At least for their manganese compound, these authors could reliably detect several reflections which should be systematically extinct in the centered unit cell; in addition, refinement of the intensity data in the subgroup Pban resulted in more realistic anisotropic displacement parameters for the 4,4'-bipy carbon atoms. The structure model in Pban implies special positions for the scattering centers with the highest electron density; for these special positions the integral reflection condition $h k l, h+k=2 n$ is fullfilled, whereas only a small part of the scattering electron density resides in general position [143]. This fact explains why the diffraction pattern for this class of compounds might have been interpreted in the super group Cmmm rather than in the correct space group. Several of the entries in Table 2, in particular the space group assignment for $\left[\mathrm{Cd}(\mu-\mathrm{Cl})_{2}\left(4,4{ }^{\prime}-\mathrm{bipy}\right)\right]$ according to reference [132] and for the reaction products of $\mathrm{FeCl}_{2}$ and $\mathrm{CoCl}_{2}$ [129] should be reconsidered. However, the alternative space group Cmmm should not simply be discarded for all compounds in this class: Based on a series of temperaturedependent measurements, we are confident that the crystal structure of $\left[\mathrm{Cd}(\mu-\mathrm{I})_{2}\left(4,4^{\prime}\right.\right.$-bipy $\left.)\right]$ is correctly described in this higher symmetry; our result is in agreement with independent work by Fujita et al. [134] and Guo et al. [135].

Two of the chlorides listed in Table 2 , namely $\left[\mathrm{Zn}(\mu-\mathrm{Cl})_{2}\left(4,4^{\prime}\right.\right.$-bipy $\left.)\right]$ and $\left[\mathrm{Pb}(\mu-\mathrm{Cl})_{2}\left(4,4^{\prime}\right.\right.$-bipy $\left.)\right]$, are dynamic and undergo fascinating changes in their crystal structures as a function of temperature. It is a fortunate and rather rare feature that these changes occur without destroying single crystal samples and hence can directly be monitored on a diffractometer.

Two consecutive single-crystal to single-crystal phase transitions [138] have been observed in $\left[\mathrm{Pb}(\mu-\mathrm{Cl})_{2}\left(4,4^{\prime}-\right.\right.$-bipy $\left.)\right]$. These transformations relate a strongly distorted low temperature structure $\alpha$ via an intermediate room temperature phase $\beta$ to the arrangement of maximum symmetry $\gamma$, the so-called aristotype [144]. Scheme 4 provides an overview of the structure types and transition temperatures involved, together with basic information about symmetry and space filling. 


\begin{tabular}{|c|c|c|c|c|}
\hline low temp. phase & $322 \mathrm{~K}$ & room temp. phase & $423 \mathrm{~K}$ & high temp. phase \\
\hline$\alpha$ & $=$ & $\beta$ & & $\gamma$ \\
\hline $\begin{array}{c}P \overline{1} \\
\text { pace filling } 0.744\end{array}$ & $271 k$ & $\begin{array}{c}C 2 / m \\
\text { space filling } 0.716\end{array}$ & & $\begin{array}{c}\text { Cmmm } \\
\text { space filling } 0.678\end{array}$ \\
\hline
\end{tabular}

Scheme 4: Structures of $\left[\mathrm{Pb}(\mu-\mathrm{Cl})_{2}(4,4\right.$ '-bipy) $]$ obtained from the room temperature phase (middle) via single-crystal to singlecrystal reactions upon cooling (left) and heating (right).

If $\left[\mathrm{Pb}(\mu-\mathrm{Cl})_{2}(4,4\right.$ '-bipy) $]$ is synthesized and crystallized under ambient conditions, the $\beta$ phase is obtained. When the solid is exposed to temperatures below $271 \mathrm{~K}$, it adopts a strongly distorted structure of low symmetry and high packing efficiency: Single crystals of $\beta$ are converted into twins of the $\alpha$ modification. This low temperature phase has independently been obtained by Nordell et al. from a hydrothermal reaction [139]. In the course of the solid state transformation of $\beta$ to $\alpha$, the bipyridine $\mathrm{N}$ atoms approach their $\mathrm{Pb}$ neighbours along the chloro-bridged chain of edge-sharing octahedra: the bipy bridge moves along one step in $c$ direction, as indicated schematically in the right part of Fig. 22. The resulting $\alpha$ arrangement is favoured with respect to density and packing efficiency: The distance between neighbouring bipy bridges, corresponding to the shortest lattice translation, is reduced from 4.11 to $3.95 \AA$.

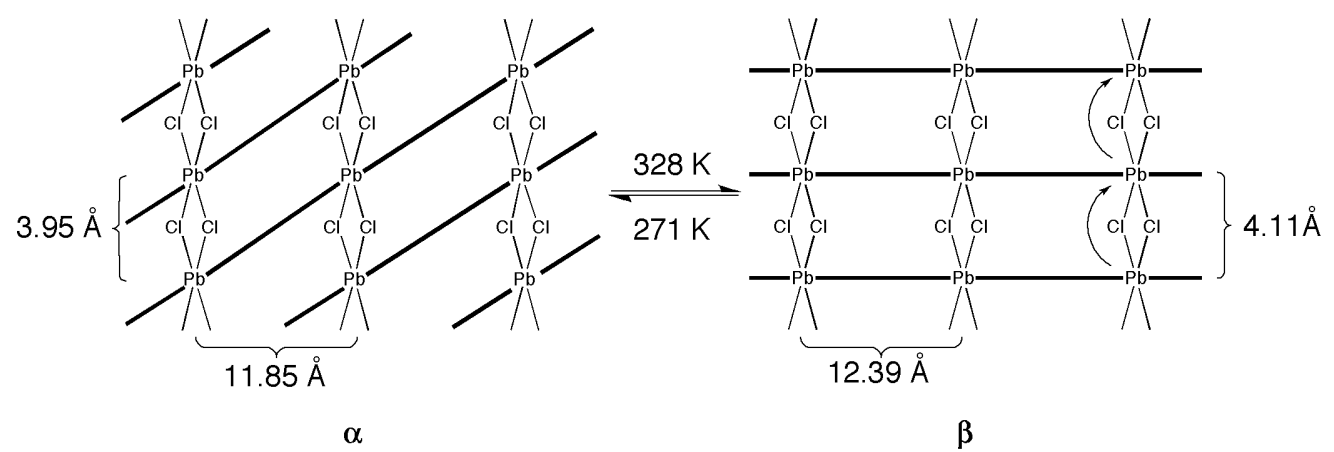

Fig. 22. Schematic relationship between the low temperature $\alpha$ and the room temperature phase $\beta$ in $\left[\mathrm{Pb}(\mu-\mathrm{Cl})_{2}\left(4,4^{\prime}-\right.\right.$-bipy $\left.)\right]$.

Remarkably, $\left[\mathrm{Pb}(\mu-\mathrm{Cl})_{2}\left(4,4^{\prime}\right.\right.$-bipy $\left.)\right]$ may also undergo a topotactic transformation in the opposite direction: When a single crystal of $\beta$ is heated to $150{ }^{\circ} \mathrm{C}$, it reversibly converts to yet another phase $\gamma$ (Fig. 23) in the supergroup Cmmm. This arrangement represents the highest possible symmetry for two-dimensional networks of the composition $\left[\mathrm{M}(\mu \text {-X })_{2}(\mu \text {-bipy) }]_{\infty}, c f\right.$. Table 2 .

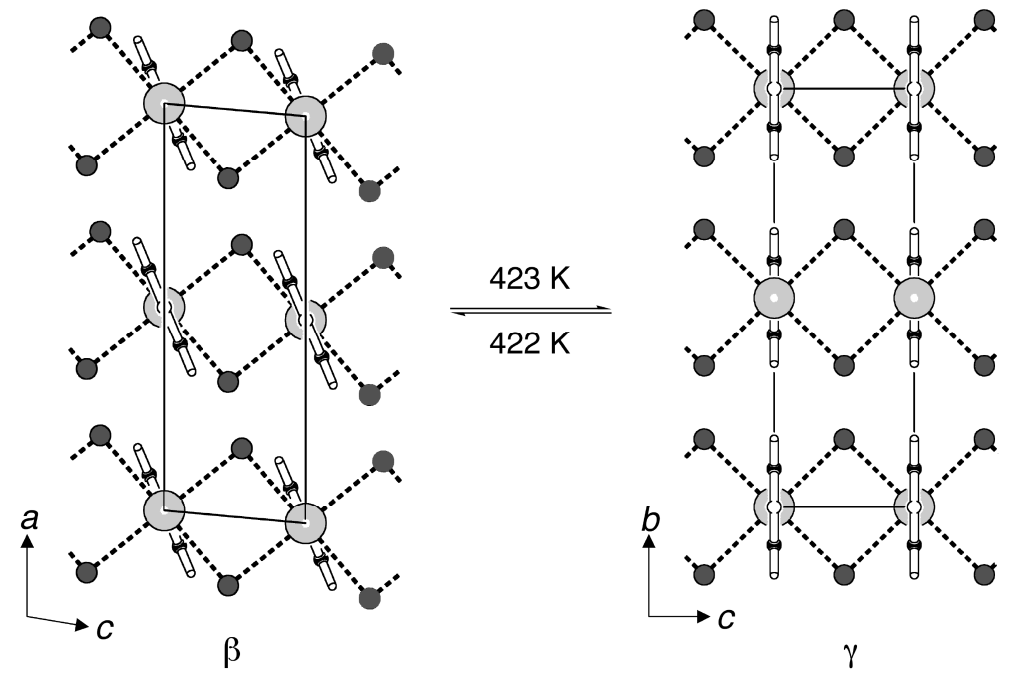

Fig. 23. Relationship between the low temperature $\alpha$ and the room temperature phase $\beta$ in $\left[\mathrm{Pb}(\mu-\mathrm{Cl})_{2}\left(4,44^{\prime}-\right.\right.$ bipy $\left.)\right]$.

The phase transition from $\beta$ to $\alpha$ is associated with substantial atom movement and therefore shows a large hysteresis; in contrast, the conformational change from $\beta$ to $\gamma$ requires only minor positional changes.

In contrast to $\left[\mathrm{Pb}(\mu-\mathrm{Cl})_{2}(4,4\right.$ '-bipy)], which retains its connectivity as a two-dimensional network in all three phases, the homologous zinc compound [ $\mathrm{ZnCl}_{2}(4,4$ '-bipy)] shows a clearcut change in topology [130]: The 2D network matching Scheme $3 \mathrm{~b}$ represents the low-temperature structure which reversibly opens up to a 4,4'-bipy bridged chain polymer with tetrahedral $\mathrm{Zn}$ (II) 
cations as shown in Fig. 24. The coexistence of both 1D chain polymers and 2D networks underlines the subtle balance between tetrahedral and octahedral coordination for $\mathrm{Zn}(\mathrm{II})$.

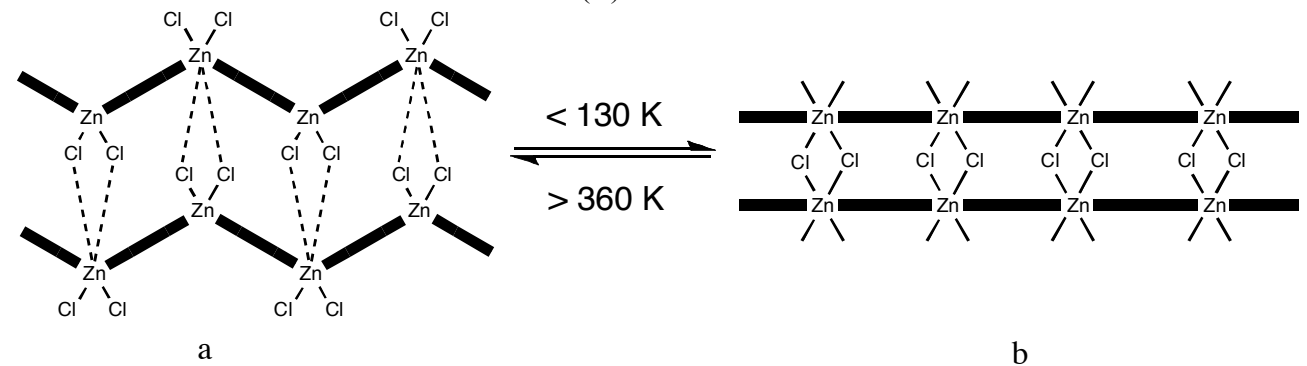

Fig. 24. Topotactic reaction in $\left[\mathrm{ZnCl}_{2}\left(4,4^{\prime}\right.\right.$-bipy) $]$. a) Zig-zag chains of $\left[\mathrm{ZnCl}_{2}\left(\mu-4,4^{\prime} \text {-bipy }\right)\right]_{\infty}^{1}$; the dashed lines between neighbouring strands indicate very long and surely not bonding $\mathrm{Zn} \cdots \mathrm{Cl}$ distances of ca. $4.6 \AA$. b) Two-dimensional network $\left[\mathrm{Zn}(\mu-\mathrm{Cl})_{2}\left(\mu-4,4^{\prime}-\text { bipy }\right)\right]_{\infty}^{2}$.

In view of the extensive rearrangement of the structure, the single-crystal to single-crystal nature of the reaction and the very low conversion temperature are particularly remarkable. Bulk quantities of the chain polymer $\left[\mathrm{ZnCl}_{2}\left(\mu-4,4^{\prime} \text {-bipy) }\right]_{\infty}^{1}\right.$ are easily available at ambient temperature and may be converted into the 2D structure simply by immerging the sample into liquid dinitrogen. The large hysteresis in the equilibrium facilitates the characterization of both topologies in the bulk by X-ray powder diffraction.

Although the topotactic nature of the dynamical behaviour in $\left[\mathrm{Pb}(\mu-\mathrm{Cl})_{2}(4,4\right.$ '-bipy $\left.)\right]$ and $\left[\mathrm{ZnCl}_{2}(4,4\right.$ '-bipy $\left.)\right]$ must be considered a fortunate coincidence, it reveals an important systematic behind the 2D networks compiled in Table 2: For metal centers such as divalent cadmium, the highly symmetric two-dimensional layer structure with halide bridges in one direction and bipy linkers perpendicular to the resulting chains is stable over a wide range of temperatures. Zn(II) represents one of the smallest cations for which the same topology can be established; only at very low temperature this efficiently packed and hence low entropy phase shows sufficient stability. The opposite is true for the large $\mathrm{Pb}$ (II) cations: The high-symmetry interlayer distance of $4.1 \AA$ is only acceptable at elevated temperature, when considerable conformational movement occurs and entropy can compensate the moderate space filling. Upon cooling, energy becomes dominating and the solid distorts to a structure of surprisingly low symmetry but favourable packing efficiency.

In addition to 4,4'-bipyridine, other ditopic $N$ donor ligands have successfully been used to crosslink neighbouring polymer strands. Pyrazine represents an obvious equivalent to 4,4'-bipy and acts in the same way in $\left[\mathrm{Zn}(\mu-\mathrm{Cl})_{2}(\mu \text {-pyz) }]_{\infty}^{2}\right.$. This solid crystallizes in space group Cmmm [145] and may alternatively be obtained via controlled thermal decomposition [146]. In contrast, the corresponding $\left[\mathrm{M}(\mu-\mathrm{X})_{2}(\mu \text {-pyz) }]_{\infty}^{2}\right.$ derivatives for $\mathrm{M}=\mathrm{Cu}, \mathrm{X}=\mathrm{Cl}[147], \mathrm{M}=\mathrm{Cu}, \mathrm{X}=\mathrm{Br}[148]$ and $\mathrm{M}=\mathrm{Hg}, \mathrm{X}=\mathrm{Cl}$ [149] are all isomorphous and adopt the subgroup $C 2 / m$, with lattice parameters rather similar to the $\mathrm{Zn}$ (II) compound.

A chiral bipyridine derivative has recently allowed to progress towards application in functional solids: The ligand $(R)-6,6{ }^{\prime}-2-$ dichloro-2,2'-2-dihydroxy1,1'-2-binaphthyl-4,4'-2-bipyridine shows axial chirality and has been employed as a linker for the construction of a homochiral porous MOF (metal-organic framework). The resulting solid has then been used to convert aromatic aldehydes to chiral secondary alcohols with high enantiomeric excess [150].

A literally more "complex" topological equivalent to 4,4'-bipy has been used by zur Loye et al.: The authors describe a series of $\mathrm{Cd}(\mu-\mathrm{Cl})_{2}$ based chain polymers in which the copper pyrazine-2-carboxylato complex shown in Fig. 25 with two dangling $N$ donor sites can act as crosslinker [151].

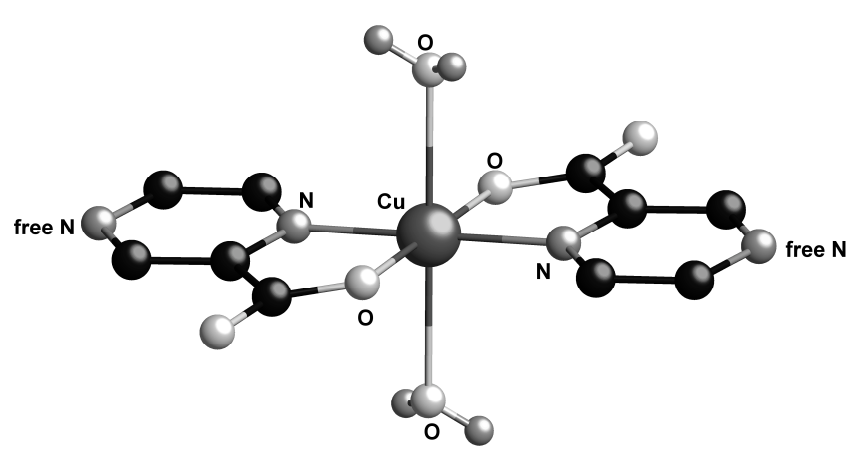

a

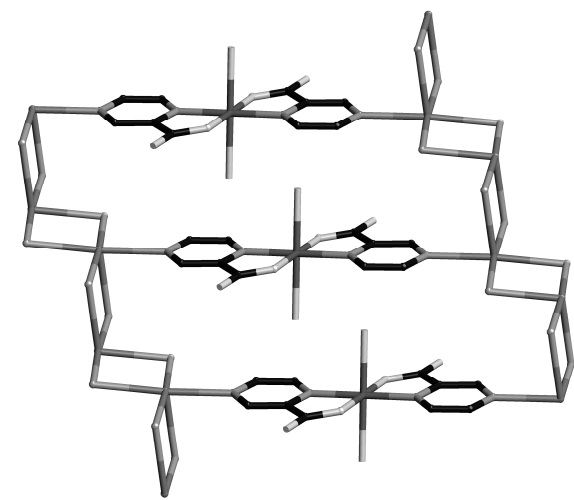

b

Fig. 25: a) $\left[\mathrm{Cu}(\text { pyzca })_{2}\left(\mathrm{OH}_{2}\right)_{2}\right]$ complex as a potential crosslinker with two free binding sites. b) $\left[\mathrm{Cu}(\text { pyzca })_{2}\left(\mathrm{OH}_{2}\right)_{2}\right]$ complexes bridging $\mathrm{Cd}(\mu-\mathrm{Cl})_{2}$ chains. Structural result from ref [151]. 
The ditopic ligand 4-cyanopyridine features two very different $N$ donor sites. Both of them coordinate $\mathrm{Cd}(\mathrm{II})$, thus crosslinking edge-sharing $\mathrm{CdI}_{2}$ chains in a cocrystal with diiodine; this solid owes its existence to charge transfer interactions between coordinated iodide and the cocrystallized diiodine [152].

In contrast to the situation with the rod-shaped spacers mentioned above such as 4,4'-bipyridine or pyrazine, crosslinking by the $N$ donor sites in the 1,3-diazine pyrimidine involves a bent geometry: $\left[\mathrm{Zn}(\mu-\mathrm{Cl})_{2}(\mu-\mathrm{pym})\right]_{\infty}^{2}$ crystallizes in the rather rare space group Pmcm [153] as a layer structure built up from corrugated sheets (Fig. 26), and the 2-aminopyrimidine derivative $\left[\mathrm{Co}(\mu-\mathrm{Cl})_{2}(\mu \text {-ampym) }]_{\infty}^{2}\right.$ is structurally related in $\mathrm{Cmcm}[154]$.

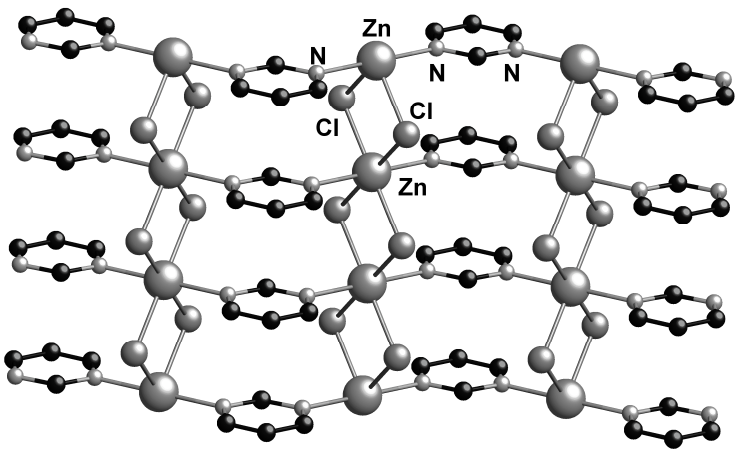

Fig. 26: Corrugated layer in $\left[\mathrm{Zn}(\mu-\mathrm{Cl})_{2}(\mu-\mathrm{pym})\right]_{\infty}^{2}$. Structural result from ref [153].

Similarly, the five-membered heterocycle 2,1,3-benzothiadiazole acts as $N, N^{\prime}$ bonded linker between $\operatorname{Co}(\mu-\mathrm{X})_{2}$ chains; the chloro- and bromo derivatives are isomorphous. $\pi$ stacking between neighbouring benzo rings contributes to the stability of this layer structure [155].

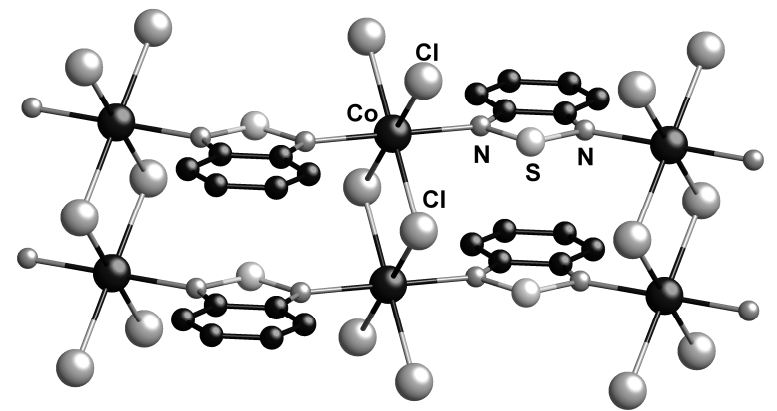

Fig. 27: Stacks of 2,1,3-benzothiadiazole ligands connecting $\operatorname{Co}(\mu-\mathrm{X})_{2}$ chains. Structural result from ref [155].

Ciani and coworkers have used the bent ditopic $N, N^{\prime}$ donor 4,4'-diaminodiphenylmethane to crosslink $\mathrm{Mn}(\mu-\mathrm{Cl})_{2}$ and $\mathrm{Cd}(\mu-$ $\mathrm{Cl})_{2}$ strands [156] to structures of higher dimensionality. In the case of the Cd network, "supramolecular isomers" [157] were identified.

Hexamethylentetramine (hmt) can bridge two, three or four cations as shown in the following examples. Ditopic hmt is encountered in the solid shown in Fig. 28: The pseudooctahedral coordination sphere at each $\mathrm{Cd}(\mathrm{II})$ in $\left[\mathrm{Cd}(\mu-\mathrm{Br})_{2}\left(\mathrm{OH}_{2}\right)\right]$ chains is occupied by an $N$ donor of a hmt-[CdBr$\left.{ }_{2}\left(\mathrm{OH}_{2}\right)_{2}\right]$-hmt moiety [158]. 


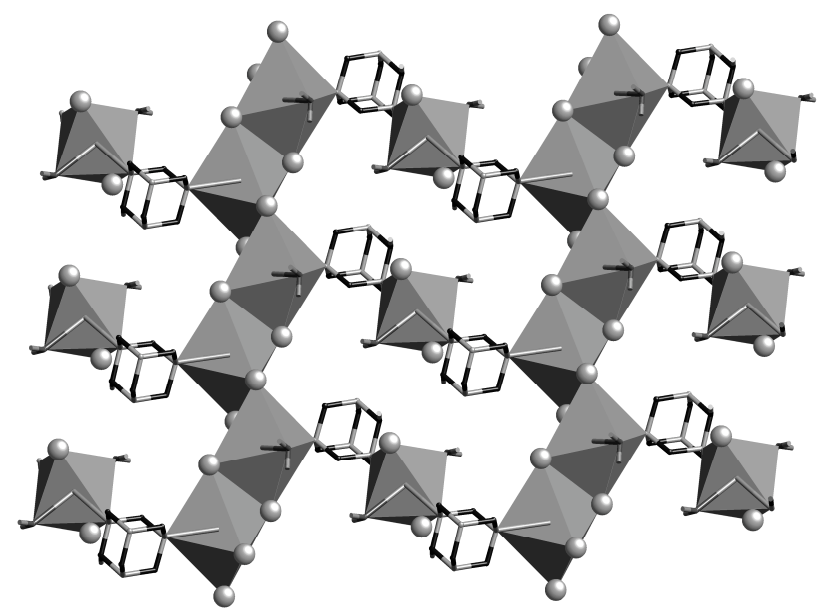

Fig. 28: Two-dimensional network from hmt- $\left[\mathrm{CdBr}_{2}\left(\mathrm{OH}_{2}\right)_{2}\right]$-hmt (horizontal) crosslinking $\left[\mathrm{Cd}(\mu-\mathrm{Br})_{2}\left(\mathrm{OH}_{2}\right)\right]$ chains (vertical). Structural result from ref [158].

Mak and Lai [159] reported an example in which three out of the four potential $N$ donor sites in hmt coordinate to $\mathrm{Cd}(\mathrm{II})$, crosslinking corner-sharing chains of the stoichiometry $\left[\mathrm{Cd}\left(\mathrm{OH}_{2}\right)_{2}(\mu-\mathrm{Cl}) \mathrm{CdCl}_{2} \mathrm{Cd}(\mu-\mathrm{Cl})\right]$.

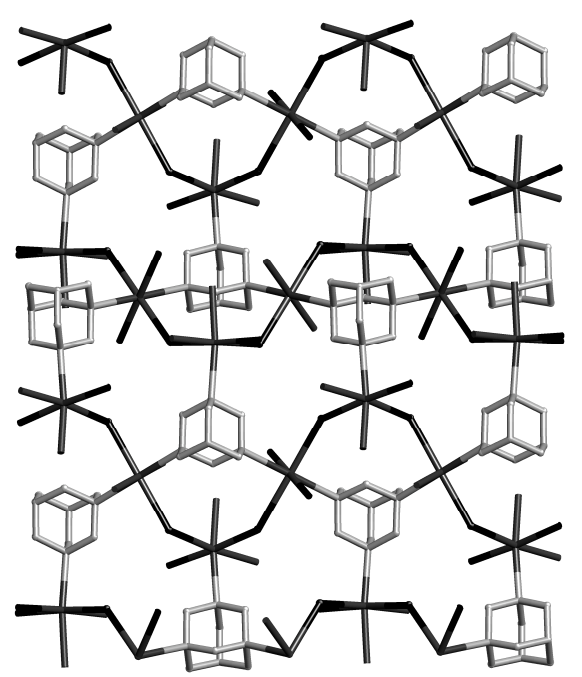

Fig. 29: $\left(\mu_{3}\right.$-hmt) moieties (drawn as grey sticks) interconnecting corner-sharing chains (extending in horizontal direction and drawn as dark sticks). Structural result from ref [159].

In $\left(\mathrm{HgCl}_{2}\right)_{2}(\mathrm{hmt})$, the hexamethylentetramine ligand coordinates to four roughly linear $\mathrm{HgCl}_{2}$ molecules; in addition to the

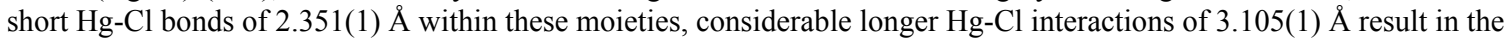
formation of edge-sharing chains with very asymmetric chloro bridges [160], similar to the situation encountered in Scheme $2 b$. The resulting structure is depicted in Fig.30.

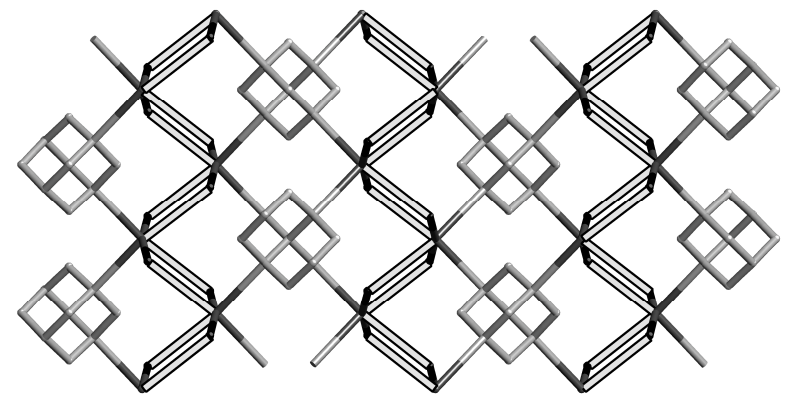

Fig. 30: $\left(\mu_{4}\right.$-hmt) linkers (drawn as grey sticks) interconnecting edge-sharing chains with very asymmetric $\mathrm{Hg}$-Cl bonds; short bonds between $\mathrm{Hg}$ and the ligands are drawn as dark sticks, long contacts as open bonds. Structural result from ref [160]. 
Chelating $N$ donor ligands may also act as crosslinkers, and their copper complexes have been studied with an emphasis on magnetic coupling through these bridges. Four of the six potential donor sites in 1,4,5,8,9,12-hexaazatriphenylene (hat) are involved in chelating two $\mathrm{Cu}(\mathrm{II})$ cations in the coordination network $\left[\mathrm{Cu}_{4}(\text { hat })_{2} \mathrm{Cl}_{8}\right]_{\mathrm{n}} \cdot 6 \mathrm{nH}_{2} \mathrm{O}$ [161]. The $\mathrm{CuCl}_{2}$ and $\mathrm{CuBr}_{2}$ adducts of bipyrimidine (bpm) are isomorphous; magnetic interaction through the bpm bridge are considerably stronger than in the case of the hat ligand [162]. Alternating oxalato and bpm bridging between corner-sharing cationic $[\mathrm{Cu}(\mu-\mathrm{Cl})]$ chains has been observed in $\left[\mathrm{Cu}_{2}(\mathrm{bpm})(\mathrm{ox}) \mathrm{Cl}_{2}\right][163]$. The latter structure is depicted in Fig. 31.

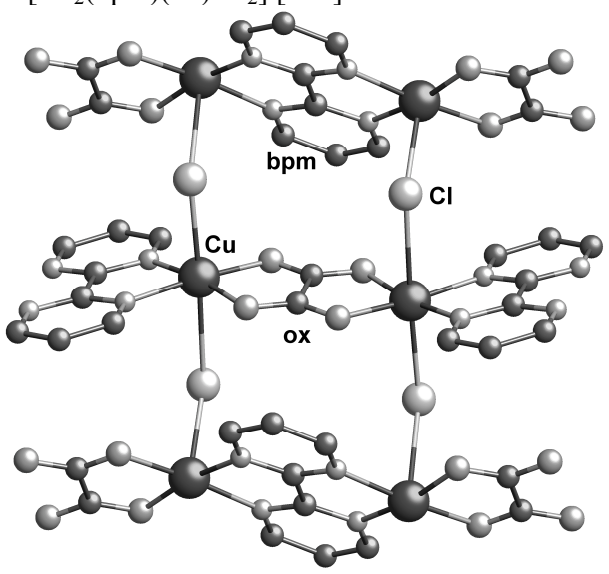

Fig. 31: Corner-sharing $[\mathrm{Cu}(\mu-\mathrm{Cl})]$ chains (vertical) are crosslinked by oxalato and bipyrimidine ligands (horizontal), Structural result from ref [163].

In the two-dimensional coordination network $\left[\mathrm{Cu}_{2} \mathrm{Cl}_{4}(\mathrm{bppz})\right]_{\mathrm{n}}$ chains exhibiting the metal-halide connectivity depicted in Scheme 1i are interconnected by the bis-chelating ligand 2,5-bis(pyridyl)pyrazine as shown in Fig. 32 [9]. The structure of this solid has been determined by powder diffraction.

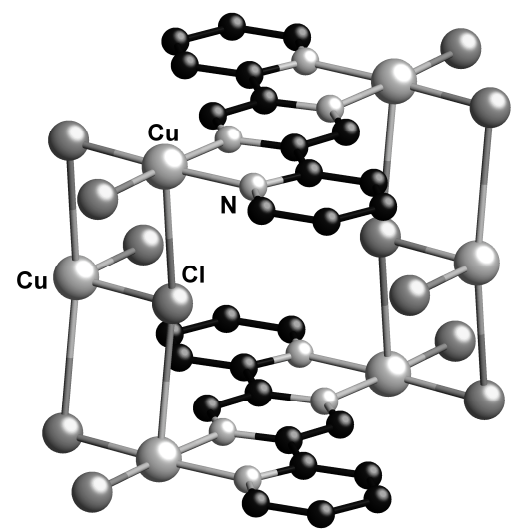

Fig. 32: Halide bridging (vertical) and bppz bridging (horizontal) in the two-dimensional coordination network $\left[\mathrm{Cu}_{2} \mathrm{Cl}_{4}(\mathrm{bppz})\right]_{\mathrm{n}}$. Structural result from ref [9].

In addition to the most popular $N$ donor crosslinkers, ligands with alternative binding sites have been employed. Bourne and Moitsheki have investigated the isomorphous solids formed by the oxygen derivative 4,4'-bipyridine- $N, N^{\prime}$-dioxide and $\mathrm{PbX}, \mathrm{X}=$ $\mathrm{Cl}, \mathrm{Br}, \mathrm{I}$ [164]. The oxygen and the sulfur atoms act as coordination sites in the heterocycle oxathian, interconnecting copper cations in neighbouring edge-sharing $\mathrm{CuCl}_{2}$ chains [165]. The bis-chelating ligand triethylene glycol dimethyl ether can act as crosslinker between $\mathrm{Cd}(\mathrm{II})$ cations in adjacent $\mathrm{CdX}_{2}$ strands; the structures of the chloride (Fig. 33) and the isomorphous bromide have been elucidated [166].

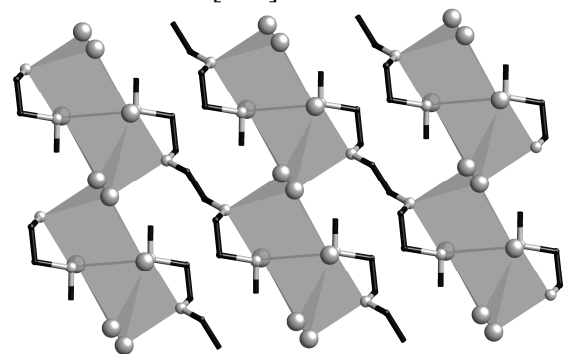

Fig. 33: Triethylene glycol dimethyl ether (drawn as sticks) interconnecting strands of $\mathrm{CdCl}_{2}$ (shown as polyhedra). Structural result from ref [166]. 


\section{Polymers with higher metal halide content}

This final chapter is devoted to solids which may be conceptually derived from the chain polymers in chapter 2 by increasing the metal halide content. Scheme 5 compiles three different prototypes: The first category in shown in Scheme 5a and covers single-chain polymers which incorporate not only donor ligand coordinated metal centers but also cations which are exclusively bonded to halides. The double chain represented in Scheme $5 \mathrm{~b}$ may be understood as the result of fusing two edge-sharing chains ( $c f$. Scheme $1 \mathrm{~g}$ ) by using every second bridging halide to replace a donor ligand in the adjacent strand; two chains of formal stoichiometry $\left[\mathrm{MX}_{2} \mathrm{~L}_{2}\right]$ will release two equivalents of donor ligands and form a product with the composition $\left[\mathrm{M}_{2} \mathrm{X}_{4} \mathrm{~L}_{2}\right]$. The products of similar fusion processes can contain metal cations exclusively bonded to halide ligands: Scheme $5 \mathrm{c}$ and $5 \mathrm{~d}$ give examples for the stoichiometry $\left[\mathrm{M}_{3} \mathrm{X}_{6} \mathrm{~L}_{4}\right]$ and $\left[\mathrm{M}_{3} \mathrm{X}_{6} \mathrm{~L}_{2}\right]$, respectively. Even broader ribbons with more inner cations may occur. In Scheme 5a, $\mathrm{c}$ and $\mathrm{d}$ cations not coordinated by any donor ligand have been highlighted in bold type.

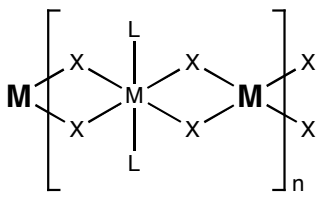

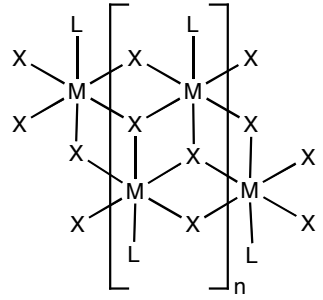

b

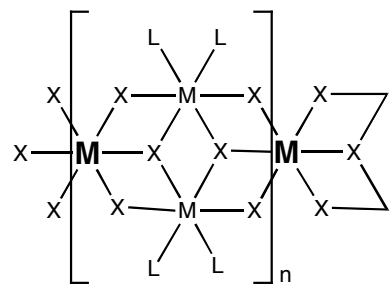

c

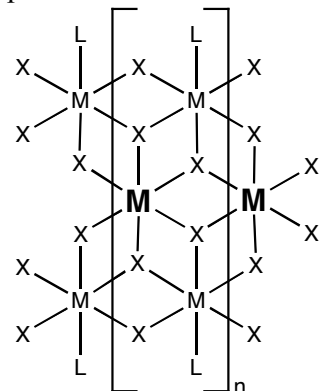

d

Scheme 5. Protoype geometries for chain polymers with high metal halide content; $M=$ divalent metal, $X=$ halogen, $L=$ donor ligand. a) Chain incorporating $\mathrm{M}$ centers (highlighted in bold) not bonded to any donor ligand, section 4.1; b) Double chains as covered in section 4.2; c,d) Segments of ribbons with M centers (highlighted in bold) not bonded to any donor ligand, $c f$. section 4.3.

\subsection{Chains incorporating unsubstituted metal halide fragments}

This section addresses single-stranded polymers containing metal centers which exclusively bind to halide ligands. The anionic chains in $\left[\mathrm{Na}_{3}\left(\mathrm{OCMe}_{2}\right)_{12}\right]\left[\mathrm{Pb}_{4} \mathrm{I}_{11}\left(\mathrm{OCMe}_{2}\right)\right]$ represent an example for this structure type: The solid contains parallel cationic and anionic chains. In the latter, face-sharing hexaiodoplumbate and acetone-pentaiodoplumbate moieties are arranged in 3:1 stoichiometry (Fig. 34); the donor ligand acetone is "diluted" along the anionic chains [167] which at the same time provide an example for the rarely encountered face-sharing of octahedra. The $\mathrm{Pb} \cdots \mathrm{Pb}$ distance between cations sharing a common face amounts to $4.047 \AA$.

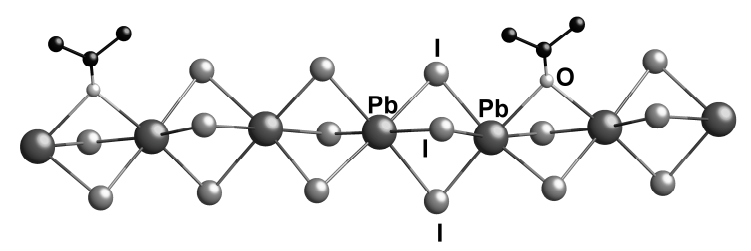

Fig. 34. Face-sharing in the anionic iodoplumbate chains in $\left[\mathrm{Na}_{3}\left(\mathrm{OCMe}_{2}\right)_{12}\right]\left[\mathrm{Pb}_{4} \mathrm{I}_{11}\left(\mathrm{OCMe}_{2}\right)\right]$. Structural result from ref [167].

$\mathrm{A}\left[\mathrm{Pb}(\mu-\mathrm{I})_{6}\right]^{-}$chain segment with similar geometric features as in the previous reference $(\mathrm{Pb} \cdots \mathrm{Pb}$ across a common iodobridged face $4.061 \AA$ ) has also been described in anionic $\left[\mathrm{Pb}_{3} \mathrm{I}_{8}(\mathrm{dmf})_{2}\right]_{\mathrm{n}}{ }^{2 \mathrm{n}-}$ chains with dimethylformamide as the donor ligand [168] and the analogous stoichiometry of the repeat unit was found for a chain polymer based on lead bromide [169]. The anionic chloronickelate chains $\left[\mathrm{Ni}_{3} \mathrm{Cl}_{8}\left(\mathrm{H}_{2} \mathrm{O}\right)_{2}\right]_{\mathrm{n}}{ }^{2 \mathrm{n}-}$ and $\left[\mathrm{Ni}_{5} \mathrm{Cl}_{14}(\mathrm{MeCN})_{2}\right]_{\mathrm{n}}{ }^{4 \mathrm{n}-}$ described by Bond and Willett [170] contain Ni(II) cations octahedrally coordinated by six bridging chloro ligands.

The metal coordination in the polymers discussed above was octahedral throughout, in part by halides only and in part involving donor ligands. We will now address the connectivity pattern sketched in Scheme 5a, with different coordination polyhedra along the chains. Sequences of alternating octahedral and tetrahedral Co(II) sites have been described by Bouwman $e t$ al. [10] for two closely related but not isomorphous chain polymers. A comparable sequence of octahedrally and tetrahedrally coordinated $\mathrm{CD}(\mathrm{II})$ cations has been found in $\left[\mathrm{Cd}(\mu-\mathrm{I})_{2} \mathrm{Cd}(\mu-\mathrm{I})_{2}(\mathrm{dmso})_{2}\right]$ [171]. McAuliffe and coworkers have studied polymers derived from $\mathrm{MnI}_{2}$ and phosphane ligands or, alternatively, by reaction of manganese powder with diiodotrimethylphosphorane [172]: The compounds $\left[\mathrm{Mn}(\mu-\mathrm{I})_{2} \mathrm{Mn}(\mu-\mathrm{I})_{2}\left(\mathrm{PMe}_{2} \mathrm{R}\right)_{2}\right](\mathrm{R}=\mathrm{Me}$ [172], $\mathrm{Ph}$ [173]) exhibit an alternating sequence of tetra- and hexacoordination; the trimethylphosphane complex is shown in Fig. 35. The derivative of the less symmmetric dimethylphenyl ligand $\mathrm{PPhMe}_{2}$ reversibly binds dioxygen in the solid state [173]. 


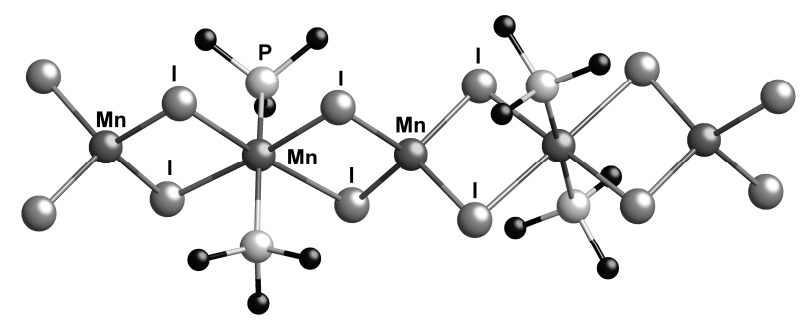

Fig. 35. Sequence of alternating octahedra and tetrahedra in $\left[\mathrm{Mn}(\mu-\mathrm{I})_{2} \mathrm{Mn}(\mu-\mathrm{I})_{2}\left(\mathrm{PMe}_{3}\right)_{2}\right]$. Structural result from ref [172].

Tetrahedra and octahedra around the same metal(II) centers are also encountered for polymeric iron compounds with the donor ligands thf [174] and isopropanol [175].

Within chain polymers of $\mathrm{Cu}(\mathrm{II})$, Jahn-Teller distortions are responsible for the coexistence of less regular polyhedra such as distorted square-planar and elongated octahedral [176] or square-pyramidal and elongated octahedral coordination [177, 178].

In the context of catalytic alkene oxidation by $\mathrm{Pd}(\mathrm{II})$ and $\mathrm{Cu}(\mathrm{I}) / \mathrm{O}_{2}$ as redox couple, the heterometallic chain shown in Fig. 36 has been described by Hosokawa, Takano and Murahashi [179]. The polymer has the composition $\left[\left\{\mathrm{Cu}(\mu-\mathrm{Cl})_{2}(\mathrm{hmpa})_{2}\right\}\{\operatorname{Pd}(\mu-\right.$ $\left.\left.\mathrm{Cl})_{2}\right\}_{2}\right]_{\infty}$ and is built up from edge-sharing pseudo-octahedral $\mathrm{Cu}(\mathrm{II})$ and square-planar $\mathrm{Pd}(\mathrm{II})$ cations.

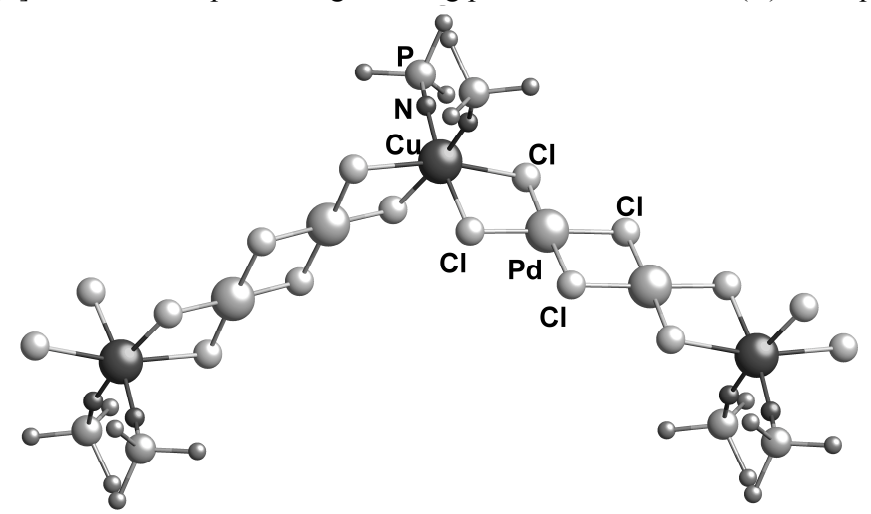

Fig. 36. Heterometallic chain in $\left[\left\{\mathrm{Cu}(\mu-\mathrm{Cl})_{2}(\mathrm{hmpa})_{2}\right\}\left\{\mathrm{Pd}(\mu-\mathrm{Cl})_{2}\right\}_{2}\right]_{\infty}$; methyl groups of the hmpa ligand have been omitted. Structural result from ref [179].

\subsection{Double chains}

The structural studies of polymers featuring the double chain connectivity in Scheme $5 \mathrm{~b}$ initiated with the X-ray structure determination of $\mathrm{NH}_{4} \mathrm{CdCl}_{3}$ by Brasseur and Pauling [180]; the anionic chains in this chlorocadmate are formed by $\left[\mathrm{Cd}_{2} \mathrm{Cl}_{6}\right]^{2-}$ rather than by $\left[\mathrm{Cd}_{2} \mathrm{Cl}_{4} \mathrm{~L}_{2}\right]$ building blocks. The authors noted the close similarity between their structure and that of cadmiumdichloride in terms of $\mathrm{Cd}-\mathrm{Cl}$ and $\mathrm{Cd} \cdots \mathrm{Cd}$ distances.

Derivatives of the soft cations of heavy post-transition metals, in particular of $\mathrm{Cd}(\mathrm{II})$, clearly dominate this and the following section. Neutral double chains are obtained with the donor ligands thioacetamide [181], imidazole [182] and monomethylurea [183]. Fig. 37 shows the polymer with thioacetamide; the imidazole derivative is isomorphous and the methylurea compound has a related structure. In all three polymers as well as in Pauling's chlorocadmate, the $\mathrm{Cd} \cdots \mathrm{Cd}$ distance along the strands corresponds to the shortest lattice parameter and ranges between 3.80 and $3.97 \AA$. The similarity between these structures is not restricted to the intrachain geometry: Projections of the unit cells in polymer direction (Fig. 38) reveal that the packing of double chains is also comparable.

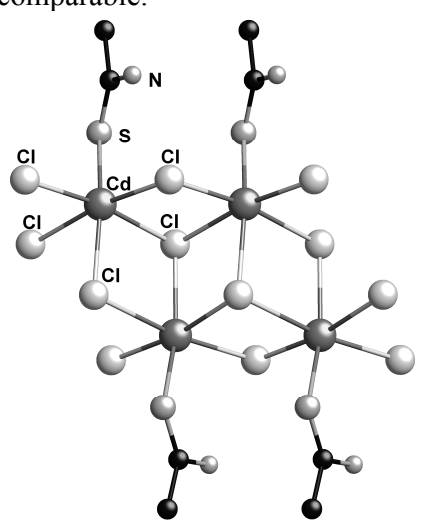

Fig. 37. Double chain in $\left[\mathrm{Cd}_{2} \mathrm{Cl}_{4}(\mathrm{taa})_{2}\right]$. Structural result from ref [181]. 


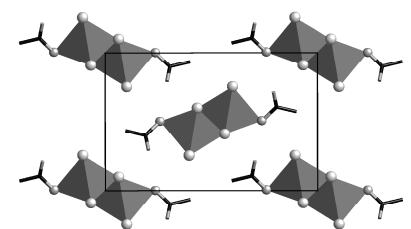

a

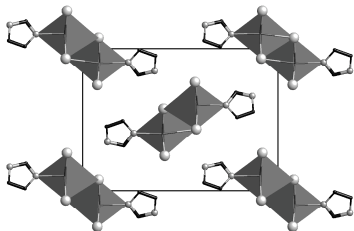

b

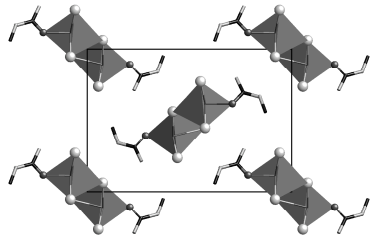

Fig. 38. Projections of $\left[\mathrm{Cd}_{2} \mathrm{Cl}_{4} \mathrm{~L}_{2}\right]$ in polymer direction; the donor ligand $\mathrm{L}$ is a) thioacetamide [181], b) imidazole [182], c) methylurea [183].

The concept of "fusing" two simple strands to a double chain has been beautifully demonstrated by Miller and coauthors [184]; in their article, the structures of both a $\left[\mathrm{FeCl}_{2}(\mathrm{MeCN})_{2}\right]$ single chain and a $\left[\mathrm{Fe}_{2} \mathrm{Cl}_{4}(\mathrm{MeCN})_{2}\right]$ double chain are reported. The latter is obtained by annealing of the former at moderate temperatures.

Cadmium chloride double chains with stoichiometry $\left[\mathrm{Cd}_{2} \mathrm{Cl}_{4}\left(\mathrm{OH}_{2}\right)_{2}\right]$ may intercalate $p$-nitroaniline and form an organicinorganic layer structure; the short lattice parameter amounts to $3.82 \AA$ [185].

Different fusion modes for the octahedra are possible: After formal re-distribution of the peripheric donor ligands, other chain types may result in the same $\left[\mathrm{Cd}_{2} \mathrm{Cl}_{4} \mathrm{~L}_{2}\right]$ stoichiometry. For example, sections in the polymer strands of $\left[\mathrm{Cd}_{2} \mathrm{Cl}_{4}\left(\operatorname{taa}_{2}\right)_{2}\right][181]$ and the zig-zag chain $\left[\mathrm{Cd}_{2} \mathrm{Cl}_{4}(\mathrm{dmso})_{2}\right][3]$ are shown in Fig. 39.
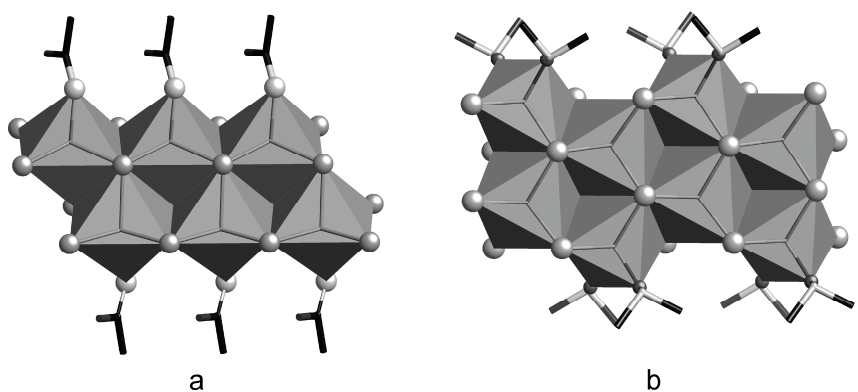

Fig. 39. Octahedra linkage in isomeric chains of a) $\left[\mathrm{Cd}_{2} \mathrm{Cl}_{4}(\mathrm{taa})_{2}\right][181]$ and b) $\left[\mathrm{Cd}_{2} \mathrm{Cl}_{4}\left(\mathrm{dmso}_{2}\right][3]\right.$.

Double chains based on $\mathrm{PbI}_{2}$ have been crosslinked with ditopic donor ligands to form layered architectures with the sequence $\mathrm{Pb}_{2} \mathrm{I}_{4}(\mathrm{~L}-\mathrm{L})_{2} \mathrm{~Pb}_{2} \mathrm{I}_{4}(\mathrm{~L}-\mathrm{L})$; the structures for $\mathrm{L}-\mathrm{L}=N, N^{\prime}$-bis(3-pyridylmethyl)-1,4-biphenylenedimethyleneimine [186] and 4,4'dipyridyl- $N, N$-dioxide (dpdo) (cf. Fig. 40) [187] have been reported.

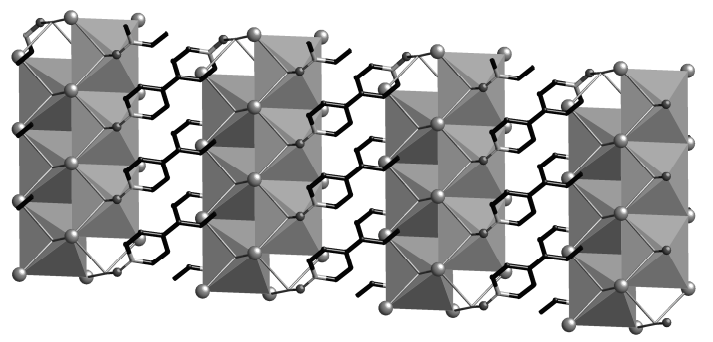

Fig. 40. Double chains of $\left[\mathrm{Pb}_{2} \mathrm{I}_{4}\right]$ (shown as polyhedra) crosslinked by dpdo (shown as stick bonds). Structural result from ref [187].

A mononegative double chain with the stoichiometry $\left[\mathrm{Cd}_{2} \mathrm{Cl}_{5}\left(\mathrm{OH}_{2}\right)\right]^{-}$, i.e. in-between the dianionic strands $\left[\mathrm{Cd}_{2} \mathrm{Cl}_{6}\right]^{2-}$ in Pauling's ammonium salt and the $\left[\mathrm{Cd}_{2} \mathrm{Cl}_{4} \mathrm{~L}_{2}\right]$ neutral double chains has been encountered in connection with a substituted imidazolium cation [188]. An anionic polymer containing the building block $\left[\mathrm{Mn}_{2} \mathrm{Cl}_{5} \mathrm{~L}\right]^{-}$, together with a cationic layer of bis(ethylenedithio)tetrathiafulvalene, was obtained by electrocrystallization [189]. This hybrid system can be considered a candidate for a functional solid becuase it combines antiferromagnetic chain polymers with organic conducting layers.

Electroneutrality in a double chain containing $\mathrm{CdCl}_{6}$ and $\mathrm{CdCl}_{5}\left(\mathrm{OH}_{2}\right)$ octahedra was achieved by coordination of two terminal chlorides to peripheric $\mathrm{Cd}(\mathrm{II})(15$-crown-5) cations [190].

Willett and coworkers [1] have used the concept of dimensional reduction and obtained a series of chlorocadmates which either belong to the double chain type described above or which represent the more fused products covered in the following section 4.3.

\subsection{Ribbons and sheets incorporating unsubstituted metal halide fragments}

These solids contain cations exclusively coordinated by halide and are reminescent of the inorganic metal halide structures. The close resemblance between pyridine- $N$-oxide derivatives of $\mathrm{CdX}_{2}, \mathrm{X}=\mathrm{Cl}, \mathrm{Br}$, I and the original halide structures has been 
recognised by Nieuwenhuyzen, Robinson and Wilkins [8]; the authors also observed that cadmium chloride was less readily degraded than the heavier halides.

Several cadmium chloride derivatives match the connectivity in Scheme 5c: The chain polymer formed with aniline follows this $\left[\mathrm{M}_{3} \mathrm{X}_{6} \mathrm{~L}_{4}\right]$ stoichiometry [191], and the ditopic donor 4,4'-diaminodiphenylmethane has been found to crosslink chains of this topology [156]. Two dmso adducts to $\mathrm{CdCl}_{2}$, a single chain and a ribbon according to Scheme 5c, coexist in the same crystal structure [3]. In variation of the connectivity depicted in Scheme $5 \mathrm{c}$, anionic chains with a repeat unit $\left[\mathrm{Cd}_{4} \mathrm{Cl}_{12}\left(\mathrm{OH}_{2}\right)\right]^{4-}$ have been described [192].

The connectivity of a neutral fusion product as depicted in Scheme $5 \mathrm{~d}$ is encountered in the $\mathrm{CdBr}_{2}$-based layer structure with bridging 4,4'-bipy; the overall stoichiometry corresponds to $\left[\mathrm{Cd}_{3} \mathrm{Br}_{6}(\mu-4,4 \text { '-bipy })\right]_{\mathrm{n}}[135]$. One of the metal halide layers is shown in Fig. 41.

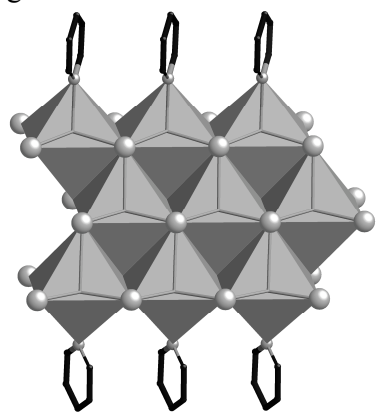

Fig. 41. Metal halide layer in $\left[\mathrm{Cd}_{3} \mathrm{Br}_{6}(\mu-4,4 \text { '-bipy })\right]_{n}$; only a section of the interconnecting 4,4 '-bipy ligands has been shown as stick bonds. Structural result from ref [135].

The composition of a considerably more complex solid may be easily derived from the $\left[\mathrm{M}_{3} \mathrm{X}_{6} \mathrm{~L}_{2}\right]$ stoichiometry in Scheme $5 \mathrm{~d}$ : With tetraphenylphosphonium counter cations, an anionic ribbon with the repeat unit $\left[\mathrm{Pb}_{15} \mathrm{I}_{34}(\mathrm{dmf})_{6}\right]^{4-}$ was crystallized [193]; this composition is obtained from five $\left[\mathrm{M}_{3} \mathrm{X}_{6} \mathrm{~L}_{2}\right]$ units when four of the donor ligands $\mathrm{L}$ in the resulting $\left[\mathrm{M}_{15} \mathrm{X}_{30} \mathrm{~L}_{10}\right]$ are replaced by halides $\mathrm{X}^{-}$. A segment of the polyanion is shown in Fig. 42.

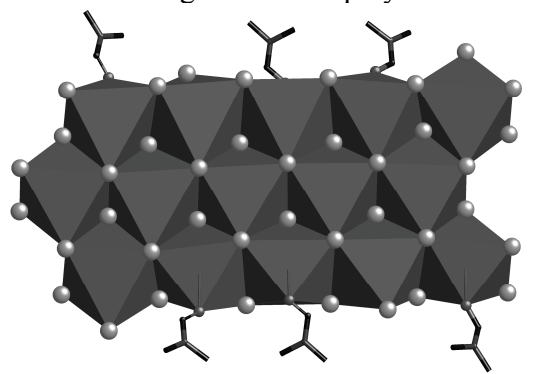

Fig. 42. $\left[\mathrm{Pb}_{15} \mathrm{I}_{34}(\mathrm{dmf})_{6}\right]^{4-}$ segment; the dmf ligands are shown as stick bonds. Structural result from ref [193].

A broader ribbon with more metal-halide rich stoichiometry than $\left[\mathrm{M}_{3} \mathrm{X}_{6} \mathrm{~L}_{2}\right]$ in Scheme $5 \mathrm{~d}$ has also been described: The anionic chain of composition $\left[\mathrm{Cd}_{5} \mathrm{Cl}_{12}\left(\mathrm{OH}_{2}\right)_{2}\right]^{2-}$ was obtained with 1-ethyl-piperidinium cations [194].

Two layer structures containing $\mathrm{Hg}(\mathrm{II})$ cations not bonded to any donor ligand shall be mentioned: $\left[\mathrm{Hg}_{3} \mathrm{I}_{6}\left(\mathrm{PMe}_{3}\right)_{2}\right]$ already introduced in section 3.1 adopts a two-dimensional network structure with octahedral and tetrahedral $\mathrm{Hg}(\mathrm{II})$ cations [127]. The $\mathrm{HgI}_{4}$ tetrahedra are irregular, with one bond considerably longer than expected [195]. In contrast, distorted octahedral coordination for all mercury centers has been observed in the solid shown in Fig. 43 [40]. The situation for the $\mathrm{Hg}$ (II) cations exclusively coordinated by halides is very similar as in the parent compound $\mathrm{HgCl}_{2}$, with two rather short $\mathrm{Hg}-\mathrm{Cl}$ bonds of ca. 2.4 $\AA$ and four considerably longer interactions [195]. This final example in the section beautifully underlines the initial statement that the subject of this review represents a meeting ground for inorganic and coordination chemistry.

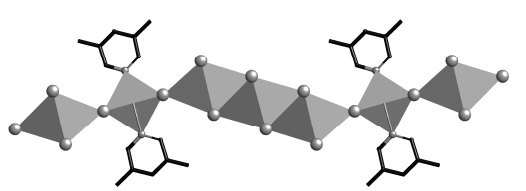

a

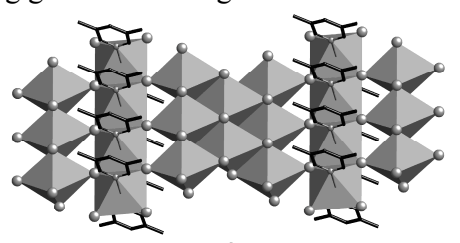

b

Fig. 43. A layer in $\left[\mathrm{Hg}(\mu-\mathrm{Cl})_{2}\left(3,5-\mathrm{Me}_{2} \text { py }\right)_{2}\left(\mu-\mathrm{HgCl}_{2}\right)_{3}\right]_{\infty}^{2}$; a) projection along the layer, b) side view. Structural result from ref [40]. 


\section{Concluding remarks}

During the work on this review, it became obvious that a complete coverage of the field can hardly be achieved. In addition to human imperfection, several rather arbitrary decisions may be responsible for these limitations. The author apologizes with all fellow scientists whose results have not been cited for one of these reasons. Polymers in which single chloro ligands, either from a $\left[\mathrm{ZnCl}_{4}\right]^{2-}[196]$ or from a $\left[\mathrm{MnCl}_{4}\right]^{2-}[197]$ moiety act as bridges between cations can be considered borderline cases. The same is true for the pseudo-halide $\mathrm{N}_{3}{ }^{-}$which can also assume the role of a linker [198]. Probably beyond the subject of this review is the isomorphous series of hexafluorosilicates and germanates in which these dianions rather than halides act as bridges between cationic $\left\{\mathrm{M}(\mathrm{II})\left(4,4^{\prime}-\text { bipy }\right)_{2}\right\}^{2+}$ layers [199, 200].

Several simple rules have been confirmed in the context of this work: Bridging fluoride can be considered an exception when compared to the heavier halides. Common vertices and edges shared by adjacent polyhedra are much more popular than facesharing. Pauling's rules about the structure of complex ionic crystals [97] may to a certain extend be relevant, but stoichiometric considerations will also contribute to the high frequency of edge-sharing geometries.

The beautiful studies devoted to the systematic degradation of the original metal dihalide structures [1-3], the impressive range of intermetal distances accomodated in the same structure type, e.g. between neighbouring cations along an edge-sharing chain ( $c f$ Table 1), and the dynamic behaviour in halide-bridged polymers $[130,138]$ convey the message why this class of compounds is so rewarding: Depending on subtle aspects of stoichiometry, size, charge or even temperature, the versatile ligands chloride, bromide and iodide may occupy either bridging or terminal coordination sites and give rise to a plethora of structures.

To my knowledge, Fausto Calderazzo has not explicitly worked on halide-bridged polymers. I had the honour and the pleasure to contribute to several of his structural studies. In the context of catena $\mathrm{Mn}$ (II) carboxylates we characterized the complex $\left[\mathrm{Mn}\left(\mu-\mathrm{O}_{2} \mathrm{CCF}_{3}\right)_{2}(\mathrm{thf})_{2}\right]_{\infty}$ [201]. The compound not only shares the topology with the cis connected edge-sharing octahedra in section 2.4 but looks surprisingly similar to $\left[\mathrm{Pb}(\mu-\mathrm{I})_{2}(2-\mathrm{Mepy})_{2}\right]_{\infty}$ by Struchkov and coworkers [202] (Fig. 44). The slightly different space filling requirements of the individual constituents cancel so efficiently that the unit cells of both compounds match very closely.

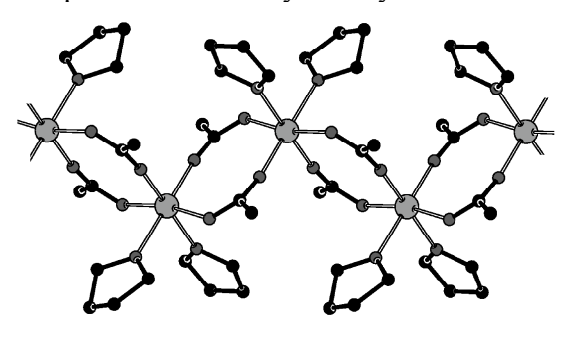

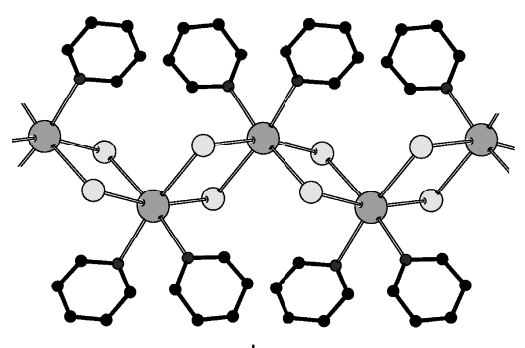

Fig. 44. Sections [203] of (a) the carboxylato-bridged polymer $\left[\mathrm{Mn}\left(\mu-\mathrm{O}_{2} \mathrm{CCF}_{3}\right)_{2}(\text { thf })_{2}\right]_{\infty}$ ref [201] and (b) the halide-bridged polymer $\left[\mathrm{Pb}(\mu-\mathrm{I})_{2}(2-\mathrm{Mepy})_{2}\right]_{\infty} \operatorname{ref}[202]$

\section{Acknowledgement}

The author wishes to thank Mr. Sebastian Kraus, Mrs. Irmgard Kalf, Dr. Beatrice Calmuschi-Cula and the anonymous reviewers for support with the manuscript.

\section{References}

[1] A. Thorn, R. D. Willet, B. Twamley, Cryst. Growth Des. 6 (2006) 1134.

[2] E. G. Tulsky, J. R. Long, Chem. Mater. 13 (2001) 1149.

[3] M. Nieuwenhuyzen, C. J. Wilkins, J. Chem. Soc. Trans. (1993) 2673.

[4] P. Sobota, J. Utko, L. B. Jerzykiewicz, Inorg. Chem. 37 (1998) 3428.

[5] The Mg compound $\left[\mathrm{Mg}(\mu-\mathrm{Cl})_{2} \mathrm{~L}_{2}\right]_{\infty}(\mathrm{L}=$ ethylformiate) features edge-sharing octahedra similar to the structures covered in section 2.4, see V.Di Noto, S. Bresadola, R. Zannetti, M. Viviani, G.Valle, G. Bandoli (1992) Z. Kristallogr. $201,161$.

[6] W. E. Marsh, E. J. Valente, D. J. Hodgson, Inorg. Chim. Acta 51 (1981) 49.

[7] L. M. Engelhardt, J. M. Patrick, C. R. Whitaker, A. H. White, Aust. J. Chem. 40 (1987) 2107.

[8] M. Nieuwenhuyzen, W. T. Robinson, C. J. Wilkins, Polyhedron 10 (1991) 2111.

[9] A. Neels, B. M. Neels, H. Stoeckli-Evans, A. Clearfield, D. Damodara, M. Poojary, Inorg. Chem. 36 (1997) 3402.

[10] J.-C. Hierso, D. D. Ellis, A. L. Spek, E. Bouwman, J. Reedijk, Chem. Commun. (2000) 1359.

[11] M. James, J. Chem Soc. Dalton Trans. (1998) 2757.

[12] M. James, J. Horvat, J. Phys. Chem. Sol. 63 (2002) 657.

[13] N. Masciocchi, C. Pettinari, E. Alberti, R. Pettinari, C. D. Nicola, A. F. Albisetti, A. Sironi, Inorg. Chem. 46 (2007) 10501.

[14] L. S. Ivashkevich, A. S. Lyakhov, M. M. Degtyarik, P. N. Gaponik, Acta Crystallogr. Sect. E 61 (2005) m394.

[15] N. Masciocchi, P. Cairati, L. Carlucci, G. Mezza, G. Ciani, A. Sironi, J. Chem. Soc. Dalton Trans. (1996) 2739.

[16] F. Allen, Acta Crystallogr. Sect. B B58 (2002) 380, all searches performed with Version 5.30 of Nov. 2008, with a total of 456637 entries. 
[17] D. C. Palmer CrystalMaker: Interactive Crystallography for MacOS, Version 7.2.1; Oxford: 2007.

[18] J. S. Stephens, D. W. J. Cruickshank, Acta Crystallogr. B26 (1970) 222.

[19] M. Cannas, F. A. Devillanova, G. Marongiu, G. Verani, J. Inorg. Nucl. Chem. 43 (1981) 2383.

[20] N. A. Bell, M. Goldstein, T. Jones, I. W. Nowell, Acta Crystallogr. Sect. B 36 (1980) 710.

[21] L. Book, C. Chieh, Acta Crystallogr. Sect. B 36 (1980) 300.

[22] A. Bell, M. Goldstein, L. A. Lorraine, I. W. Nowell, J. Chem. Soc. Dalton Trans. (1984) 1621.

[23] M. Authier-Martin, J. Hubert, R. Rivest, A. L. Beauchamp, Acta Crystallogr. Sect. B 34 (1978) 273.

[24] L. P. Battaglia, A. B. Corradi, M. Biddau, G. Ponticelli, J. Crystallogr. Spectrosc. Res. 16 (1986) 721.

[25] S. Menzer, E. C. Hillgeris, B. Lippert, Inorg. Chim. Acta 211 (1993) 221.

[26] F. Cristiani, F. A. Devillanova, F. Isaia, G. Verani, L. Battaglia, A. B. Corradi, J. Chem. Res. 32 (1989) 301.

[27] F. Bottomley, E. C. Ferris, P. S. White, Acta Crystallogr. Sect. C 45 (1989) 816.

[28] J. Cipot-Wechsler, A. A.-S. Ali, E. E. Chapman, T. S. Cameron, A. Thompson, Inorg. Chem. 46 (2007) 10947.

[29] R. R. Holmes, Prog. Inorg. Chem 32 (1984) 119.

[30] G. Bandoli, M. C. Biagini, D. A. Clemente, G. Rizzardi, Inorg. Chim. Acta 20 (1976) 71.

[31] R. A. Bream, E. D. Estes, D. J. Hodgson, Inorg. Chem. 14 (1975) 1672.

[32] W. S. Sheldrick, P. Bell, Z. Naturforsch., B: Chem.Sci 42 (1987) 195.

[33] X. Wang, J. D. Ranford, J. J. Vittal, J. Mol. Struct. 796 (2006) 28.

[34] S. J. Brown, X. Tao, T. A. Wark, D. W. Stephan, P. K. Mascharak, Inorg. Chem. 27 (1988) 1581.

[35] X.-H. Bu, M. Du, Z.-L. Shang, R.-H. Zhang, D.-Z. Liao, M. Shionoya, T. Clifford, Inorg. Chem. 39 (2000) 4190.

[36] R. Cortes, L. Lezama, J. I. R. d. Larramendi, G. Madariaga, J. L. Mesa, F. J. Zuniga, T. Rojo, Inorg. Chem. 34 (1995) 778.

[37] T. Rojo, R. Cortés, J. I. R. d. Larramendi, G. Madariaga, J. Chem. Soc. Dalton Trans. (1992) 2125.

[38] T. Rojo, J. L. Mesa, M. I. Arriortua, J. M. Savariault, J. Galy, G. Villeneuve, D. Beltran, Inorg. Chem. 27 (1988) 3904.

[39] A. Chiesi-Villa, A. G. Manfredotti, M. Nardelli, G. Pelizzi, J. Chem. Cryst. 1 (1971) 245.

[40] C. Hu, I. Kalf, U. Englert, CrystEngComm 9 (2007) 603.

[41] S. M. Godfrey, D. G. Kelly, A. G. Mackie, P. P. M. Rory, C. Y. McAuliffe, R. G. Pritchard, S. M. Watson, J. Chem. Soc.

Dalton Trans. (1991) 1447.

[42] N. A. Bell, T. D. Dee, M. Goldstein, I. W. Nowell, Inorg. Chim. Acta 38 (1980) 191.

[43] C. Hebecker, Z. Anorg. Allg. Chem. 384 (1971) 111.

[44] M. Cannas, G. Marongiu, G. Saba, J. Chem. Soc. Dalton (1980) 2090.

[45] D. J. Hodgson, D. K. Towle, W. E. Hatfield, Inorg. Chim. Acta 179 (1991) 275.

[46] J. Yamada, H. Hashimoto, Y. Inomata, T. Takeuchi, Bull. Chem. Soc. Jpn. 67 (1994) 3224.

[47] R. J. Pleus, H. Waden, W. Saak, D. Haase, S. Pohl, J. Chem. Soc. Dalton Trans. (1999) 2601.

[48] J. Pickardt, I. Hoffmeister, Z. Naturforschung B: Chem. Sci. 50 (1995) 828.

[49] A. Wojtczak, Acta Crystallogr. Sect. C 43 (1987) 645.

[50] K. T. Szacilowski, P. Xie, A. Y. S. Malkhasian, M. J. Heeg, M. Y. Udugala-Ganehenege, L. E. Wenger, J. F. Endicott, Inorg.

Chem. 44 (2005) 6019.

[51] H. Zhang, Y.-M. Wu, L. Fang, Acta Crystallogr. Sect. E 62 (2006) 1459.

[52] R. E. Caputo, R. D. Willett, Acta Crystallogr. Sect. B 37 (1981) 1616.

[53] W. Depmeier, Acta Crystallogr. Sect. B 36 (1980) 1065.

[54] D. R. Taylor, J. C. Calabrese, E. M. Larsen, Inorg. Chem. 16 (1977) 721.

[55] D. Harker, Z. Kristallogr. 93 (1936) 136.

[56] C. H. McGillivray, J. M. Bijvoet, Z. Kristallogr. 94 (1936) 231.

[57] L. J. De Jongh, A. R. Miedema, Adv. Phys. 23 (1974) 1.

[58] I. Pabst, J. W. Bats, Acta Crystallogr. Sect. C 41 (1985) 1297.

[59] D. B. Losee, N. McElearney, G. E. Shankle, R. L. Carlin, Phys. Rev. B 8 (1973) 2185.

[60] R. E. Caputo, R. D. Willett, Acta Crystallogr. Sect. B 32 (1976) 2639.

[61] R. Hoogerbeets, S. A. J. Wiegers, A. J. v. Duyneveldt, R. D. Willett, U. Geiser, Physica 125 B (1984) 135.

[62] G. Thiele, G. Wittenburg, Acta Crystallogr. Sect. C C54 (1998) 764.

[63] R. E. Greeney, C. P. Landee, Phys. Rev. B 39 (1989) 200.

[64] R. E. Greeney, C. P. Landee, J. H. Zhang, W. M. Reiff, Inorg. Chem. 29 (1990) 3119.

[65] D. P. Mellor, C. D. Coryell, J. Am. Chem. Soc. 60 (1938) 1786.

[66] J. D. Dunitz, Acta Crystallogr. 10 (1957) 307.

[67] L. Cavalca, M. Nardelli, G. Fava, Acta Crystallogr. 13 (1960) 594.

[68] J. R. Ferraro, K. C. Davis, Inorg. Chim. Acta 3 (1969) 685.

[69] C. Hu, U. Englert, CrystEngComm 3 (2001) 91.

[70] M. Goldstein, R. J. Hughes, Inorg. Chim. Acta 40 (1980) 229.

[71] M. Goldstein, R. J. Hughes, Inorg. Chim. Acta 37 (1979) 71.

[72] M. Goldstein, W. D. Unsworth, J. Mol. Struct. 14 (1972) 451.

[73] M. Goldstein, W. D. Unsworth, Inorg. Chim. Acta 4 (1970) 342.

[74] G. Bhosekar, I. Jeß, N. Lehnert, C. Näther, Eur. J. Inorg. Chem. (2008) 605.

[75] C. Hu, U. Englert, Acta Crystallogr. Sect. C 57 (2001) 1251.

[76] R. Zannetti, Gazz. Chim. Ital. 90 (1960) 328.

[77] R. Wang, C. W. Lehmann, U. Englert, Acta Crystallogr. Sect. B accepted for publication.

[78] C. Hu, U. Englert, CrystEngComm 4 (2002) 20. 
[79] A. Erdonmez, D. Ulku, Z. Kristallogr. 165 (1983) 241.

[80] J. A. C. van Ooijen, J. Reedijk, E. J. Sonneveld, J. W. Visser, Transition Met. Chem. 4 (1979) 305.

[81] U. Englert, S. Schiffers, Acta Crystallogr. Sect. E 62 (2006) m295.

[82] M. Lubben, A. Meetsma, B. L. Feringa, Inorg. Chim. Acta 230 (1995) 169.

[83] J. Han, J. Fang, Y. Dong, H. Chang, Acta Crystallogr. Sect. E 62 (2006) m183.

[84] J.-H. Yu, L. Ye, M.-H. Bi, Q. Hou, X. Zhang, J.-Q. Xu, Inorg. Chim. Acta 360 (2007) 1987.

[85] J. S. Casas, E. E. Castellano, J. Ellena, M. S. Garcia-Tasende, A. Sanchez, J.Sordo, M. J. Vidarte, Main Group Met. Chem. $24(2001) 455$.

[86] M. T. Garland, D. Grandjean, E. Spodine, A. M. Atria, J. Manzur, Acta Crystallogr. Sect. C 44 (1988) 1209.

[87] A. M. Atria, R. Baggio, M. T. Garland, O. Gonzalez, J. Manzur, O. Pena, E. Spodine, J. Crystallogr. Spectrosc. Res. 23 (1993) 943.

[88] R. D. Willett, G. Pon, C. Nagy, Inorg. Chem. 40 (2001) 4342.

[89] H.-X. Guo, L.-M. Yang, Z.-X. Lin, X.-J. Zou, Acta Crystallogr. Sect. E 62 (2006) m2863.

[90] X. Sui, X. Lu, J. Feng, S. Wang, P. Li, J. Coord. Chem. 61 (2008) 1568.

[91] F. Keij, R. A. G. d. Graaff, J. G. Haasnoot, A. J. Oosterling, E. Pedersen, I. Reedijk, J. Chem. Soc. Chem. Commun. (1988) 423.

[92] A. Oosterling, R. A. G. d. Graaff, J. G. Haasnoot, F. S. Keij, J. Reedijk, E. Pedersen, Inorg. Chim. Acta 163 (1989) 53.

[93] R. Sillanpää, T. Nortia, Inorg. Chim. Acta 83 (1984) 111.

[94] C. F. Huang, H. H. Wei, G. H. Lee, Y. Wang, Inorg. Chim. Acta 279 (1998) 233.

[95] G. D. Andreetti, L. Cavalca, M. A. Pellin-Ghelli, P. Sgarabotto, Gazz. Chim. Ital. 101 (1971) 488.

[96] F. Cariati, G. Ciani, L. Menabue, G. C. Pellacani, G. Rassu, A. Sironi, Inorg. Chem. 22 (1983) 1897.

[97] L. Pauling, J. Am. Chem. Soc. 51 (1929) 1010.

[98] A. W. Schlueter, R. A. Jacobson, R. E. Rundle, Inorg. Chem. 5 (1966) 277.

[99] U. Englert, S. Schiffers, Acta Crystallogr. Sect. E 62 (2006) m194.

[100] Y. Chen, Y.-L. Wang, S.-M. Ying, S.-L. Cai, Acta Crystallogr. Sect. E 63 (2007) m2751.

[101] P. Nockemann, G. Meyer, Acta Crystallogr. Sect. E 60 (2004) m751.

[102] P. Nockemann, G. Meyer, Acta Crystallogr. Sect. E 60 (2004) m753.

[103] F. Bigoli, M. Lanfranchi, M. A. Pellinghelli, J. Chem. Res. 214 (1990) 1712.

[104] W. Ouellette, B. S. Hudson, J. Zubieta, Inorg. Chem. 46 (2007) 4887; in this structure of formal composition CdCl(trz), the $N$ donor in 4 position acts as an additional crosslink to a neighbouring chain.

[105] L. S. Ivashkevich, A. S. Lyakhov, P. N. Gaponik, M. M. Degtyarik, O. A. Ivashkevich, S. I. Tiutiunnikov, V. V. Efimov, Acta Crystallogr. Sect. C 62 (2006) m607.

[106] S. Kuriyama, Y. Inamoto, Y. Arai, F. S. Howell, J. Inorg. Biochem. 100 (2006) 1299.

[107] X.-M. Chen, T. C. W. Mak, J. Crystallogr. Spectrosc. Res. 21 (1991) 27.

[108] K. I. Schaffers, D. A. Keszler, Acta Crystallogr. Sect. C 49 (1993) 1156.

[109] J. Schreuer, S. Haussuhl, Z. Kristallogr. 205 (1993) 313.

[110] B. J. Graves, D. J. Hodgson, Inorg. Chem. 20 (1981) 2223.

[111] S. M. Nelson, G. McFall, M. G. B. Drew, A. H. B. Othman, N. B. Mason, J. C. S. Chem. Commun. (1977) 167.

[112] R. E. Marsh, Inorg. Chem. 29 (1990) 572.

[113] B. C. U. Nair, J. E. Sheats, R. Ponteciello, D. V. Eugen, V. Petrouleas, G. C. Dismukes, Inorg. Chem. 28 (1989) 1582.

[114] P. B. Hitchcock, T. H. Lee, G. J. Leigh, Dalton Trans. (2003) 2276.

[115] P. L'Haridon, M. T. L. Bihan, Acta Crystallogr. Sect. B 29 (1973) 2195.

[116] C. Yue, Z. Lin, L. Chen, F. Jiang, M. Hong, J. Mol. Struct. 779 (2005) 16.

[117] C. Janiak, J. Chem. Soc. Dalton Trans. (2003) 2781.

[118] F. P. Gortsema, R. Didchenko, Inorg. Chem. 4 (1964) 182.

[119] Y. Shvedenkov, A. V. Virovets, L. G. Lavrenova, Izv. Akad. Nauk SSSR, Ser. Khim. (2003) 1281.

[120] D. O. Ivashkevich, A. S. Lyakhov, P. N. Gaponik, A. A. Govorova, Acta Crystallogr. Sect. E 57 (2001) m335.

[121] L. S. Ivashkevich, A. S. Lyakhov, M. M. Degtyarik, P. N. Gaponik, Zh. Neorg. Khim. 50 (2005) 82.

[122] A. V. Virovets, N. V. Podberezskaya, L. G. Lavrenova, Acta Crystallogr. Sect. C C51 (1995) 1084.

[123] A. V. Virovets, I. A. Baiidina, V. I. Alekseev, N. V. Podberezskaya, L. G. Lavrenova, Zh. Strukt. Khim. 37 (1996) 330.

[124] L. S. Ivashkevich, A. S. Lyakhov, T. V. Serebryanskaya, P. N. Gaponik, Acta Crystallogr. Sect. E 64 (2008) m1044.

[125] Y. Shvedenkov, M. Bushuev, G. Romanenko, L. Lavrenova, V. Ikroskii, P. Gaponik, S. Larinonov, Eur. J. Inorg. Chem. (2005) 1678.

[126] A. F. Stassen, H. Kooijman, A. L. Spek, L. J. d. Jongh, J. G. Haasnoot, J. Reedijk, Inorg. Chem. 41 (2002) 6468.

[127] N. A. Bell, L. A. March, Inorg. Chim. Acta 179 (1991) 73.

[128] A. M. Chippindale, A. R. Cowley, K. J. Peacock, Acta Crystallogr. Sect. C 56 (2000) 651.

[129] M. A. Lawandy, X. Huang, R.-J. Wang, J. Li, J. Y. Lu, T. Yuen, C. L. Lin, Inorg. Chem. 38 (1999) 5410.

[130] C. Hu, U. Englert, Angew. Chem. Int. Ed. 44 (2005) 2281.

[131] C. Hu, Q. Li, U. Englert, CrystEngComm 5 (2003) 519.

[132] B.-Y. Lou, R.-H. Wang, Y. Xu, D.-Q. Yuan, Y.-F. Zhou, M.-C. Hong, Jiegou Huaxue 23 (2004) 747.

[133] W.-T. Chen, X.-N. Fang, Q.-Y. Luo, Y.-P. Xu, Y.-P. Duan, Acta Crystallogr. Sect. C 63 (2007) m398.

[134] K. Biradha, M. Fujita, J. Incl. Phen. Macrocyc. Chem. 49 (2001) 201.

[135] W.-T. Chen, M.-S. Wang, X. Liu, Guo, J.-S. Huang, Cryst. Growth Des. 6 (2006) 2289.

[136] Y.-M. Xie, J.-H. Wu, Acta Crystallogr. Sect. C 63 (2007) m220. 
[137] L. Pan, N. Zheng, Y. Wu, S. Yu, X. Huang, Acta Crystallogr. Sect. C 55 (1999) 343.

[138] C. Hu, U. Englert, Angew. Chem. Int. Ed. 45 (2006) 3457.

[139] K. J. Nordell, K. N. Schultz, K. A. Higgins, M. D. Smith, Polyhedron 23 (2004) 2161.

[140] Y. Cui, J. Ren, G. Chen, W. Yu, Y. Qian, Acta Crystallogr. Sect. C 56 (2000) e552.

[141] H.-D. Yin, J.-C. Cui, Chem. Res. Chin. Univ 20 (2004) 548.

[142] Y.-J. Shi, Y. Xu, Y. Zhang, B. Huang, D.-R. Zhu, C.-M. Jin, H.-G. Zhu, Z. Yu, X.-T. Chen, X.-Z. You, Chem. Lett. (2001) 678.

[143] T. Hahn, International Tables for Crystallography, Vol. A. 5 ed.; Kluwer Academic Publishers: Dordrecht, The

Netherlands, 2002.

[144] H. Bärnighausen, MATCH 9 (1980) 139.

[145] J. Pickardt, B. Staub, Z. Naturforsch. B Chem. Sci. 51 (1996) 947.

[146] G. Bhosekar, I. Jess, C. Näther, Inorg. Chem. 45 (2006) 6508.

[147] J. Pickardt, B. Staub, Z. Naturforsch. B Chem. Sci. 52 (1997) 1456.

[148] T. Fetzer, A. Lentz, T. Debaerdemaeker, Z. Naturforsch. B Chem. Sci. 44 (1989) 553.

[149] P. Nockemann, G. Meyer, Acta CrystAllogr. Sect. E 60 (2004) m744.

[150] C.-D. Wu, A. Hu, L. Zhang, W. Lin, J. Am. Chem. Soc. 127 (2005) 8940.

[151] D. M. Ciurtin, M. D. Smith, H.-C. z. Loye, Dalton Trans. (2003) 1245.

[152] R. D. Bailey, L. L. Hook, W. T. Pennington, Chem. Commun. (1998) 1181.

[153] J. Pickardt, B. Staub, Z. Naturforsch. B Chem. Sci. 51 (1996) 947.

[154] R. D. Pike, M. J. Lim, E. A. L. Willcox, T. A. Tronic, J. Chem. Cryst. 36 (2006) 781.

[155] G. S. Papaefstathiou, S. P. Perlepes, A. Escuer, R. Vicente, A. Gantis, C. P. Raptopoulou, A. Tsohos, V. Psycharis, A.

Terzis, J. Sol. State Chem. 159 (2001) 371.

[156] L. Carlucci, G. Ciani, D. M. Proserpio, F. Porta, Cryst. Eng. Comm. 8 (2006) 696.

[157] B. Moulton, M. J. Zaworotko, Chem. Rev. 101 (2001) 1629.

[158] M.-L. Tong, S.-L. Zheng, X.-M. Chen, Acta Crystallogr. Sect. C 56 (2000) 960.

[159] T.-F. Lai, T. C. W. Mak, Z. Kristallogr. 165 (1983) 105.

[160] S. R. Batten, A. R. Harris, K. S. Murray, J. P. Smith, Crystal Growth \& Design 2 (2002) 87.

[161] H. Grove, J. Sletten, M. Julve, F. Lloret, J. Chem. Soc. Dalton Trans. (2001) 1029.

[162] M. Julve, G. D. Munno, G. Bruno, M. Verdaguer, Inorg. Chem. 27 (1988) 3160.

[163] S. Decurtins, H. W. Schmalle, P. Schneuwly, L.-M. Zhent, J. Ensling, A. Hauser, Inorg. Chem. 34 (1995) 5501.

[164] S. A. Bourne, L. J. Moitsheki, J. Chem. Cryst. 37 (2007) 359.

[165] J. C. Barnes, J. D. Paton, A. McKissock, Acta Crystallogr. Sect. C 39 (1983) 547.

[166] C. C. Hines, W. M. Reichert, S. T. Griffin, A. H. Bond, P. E. Snowwhite, R. D. Rogers, J. Mol. Struct. 796 (2006) 76.

[167] H. Krautscheid, J.-F. Lekieffre, J. Besinger, Z. anorg. allg. Chem. 622 (1996) 1781.

[168] H.-H. Li, Z.-R. Chen, J.-Q. Li, C.-C. Huang, G.-C. Xiao, Z.-X. Lian, X.-L. Hu, Huaxue Xuebao (Acta Chim. Sinica) 63 (2005) 697.

[169] H. Gröger, C. Lode, H. Vollmer, H. Krautscheid, Z. anorg. allg. Chem. 628 (2002) 57.

[170] B. M. R. Bond, R. D. Willett, Acta Crystallogr. Sect. C 49 (1993) 861.

[171] M. Nieuwenhuyzen, H. Wen, C. J. Wilkins, Z. anorg. allg. Chem. 615 (1992) 143.

[172] C. A. McAuliffe, S. M. Godfrey, A. G. Mackie, R. G. Pritchard, J. Chem. Soc. Chem. Commun. (1992) 483.

[173] B. Beagley, J. C. Briggs, A. Hosseiny, W. E. Hill, T. J. King, C. A. McAuliffe, K. Minten, Chem. Commun. (1984) 305.

[174] P. B. Hitchcock, T. H. Lee, G. J. Leigh, Inorg. Chim. Acta 348 (2003) 199.

[175] G. G. Nunes, R. C. R. Bottini, D. M. Reis, P. H. C. Camargo, D. J. Evans, P. B. Hitchcock, G. J. Leigh, E. 1. Sa, J. F.

Soares, Inorg. Chim. Acta 357 (2004) 1219.

[176] P. C. Christidis, C. A. Bolos, G. S. Nikolov, Inorg. Chim. Acta 237 (1995) 123.

[177] R. Bhattacharya, A. Ghosh, M. S. Ray, L. Righi, G. Bocelli, S. Caudhuri, R. D. Willett, J. M. Clemente-Juan, E. Coronado,

C. J. Goméz-Garcia, Eur. J. Inorg. Chem. (2003) 4253.

[178] M. Czugler, L. Kótai, B. Sreedhar, A. Rockenbauer, I. Gács, S. Holly, Eur. J. Inorg. Chem. (2002) 3298.

[179] T. Hosokawa, M. Takano, S.-I. Murahashi, J. Am. Chem. Soc. 118 (1996) 3990.

[180] H. Brasseur, L. Pauling, J. Am. Chem. Soc. 60 (1938) 2886.

[181] M. M. Rolies, C. J. d. Ranter, Acta Crystallogr. Sect. B 34 (1978) 3216.

[182] L. R. Nassimbeni, A. L. Rodgers, Acta Crystallogr. Sect. B 32 (1976) 257.

[183] M. Nardelli, L. Coghi, G. Azzoni, Gazz. Chim. Ital. 88 (1958) 235.

[184] K. I. Pokhodnya, M. Bonner, A. G. DiPasquale, A. L. Rheingold, J.-H. Her, P. W. Stephens, J.-W. Park, B. S. Kennon, A. M. Arif, J. S. Miller, Inorg. Chem. 46 (2007) 2471.

[185] G. F. Volodina, A. V. Ablov, Dokl. Akad. Nauk SSSR (Proc. Nat. Acad. Sci. USSR) 182 (1968) 105.

[186] L.-Y. Kong, Z.-H. Zhang, T.-a. Okamura, M.-J. Fei, W.-Y. Sun, N. Ueyama, Chem. Lett. 33 (2004) 1572.

[187] Y. J. Wang, H. H. Li, Z. R. Chen, C. C. Huang, X. H. Huang, M. Feng, Y. Lin, Cryst. Eng. Comm. 10 (2008) 770.

[188] X. Shi, J. Zhang, T.-K. Ying, G.-L. Zhao, Acta Crystallogr. Sect. E 63 (2007) m2157.

[189] H. Miyasaka, Y. Yoshino, T. Ishii, R. Kanehama, T. Manabe, M. Yamashita, H. Nishikawa, I. Ikemoto, H. Kishida, H. Matsuzaki, H. Okamoto, J. Solid State Chem. 168 (2002) 418.

[190] A. Hazell, G. Hazell, Acta Crystallogr. Sect. C 47 (1991) 730.

[191] A. V. Ablov, G. F. Volodina, L. I. Kabachenko, I. F. Burshtein, V. Y. Ivanova, T. I. Malinovskii, Dokl. Akad. Nauk SSSR

(Proc. Nat. Acad. Sci. USSR) 251 (1980) 897. 
[192] A. Garcia-Raso, J. J. Fiol, A. Tasada, F. M. Alberti, F. Badenas, X. Solans, M. Font-Bardia, Polyhedron 26 (2007) 949. [193] H. Krautscheid, J.-F. Lekieffre, J. Besinger, Z. anorg. allg. Chem. 622 (1996) 1781.

[194] A. B. Corradi, M. R. Cramarossa, G. C. Pellacani, L. P. Battaglia, Gazz. Chim. Ital. 124 (1994) 481.

[195] A. F. Wells, Structural Inorganic Chemistry. 5 ed.; Clarendon Press: Oxford, 1984.

[196] O. V. Pryma, S. R. Petrusenko, V. N. Kokozay, B. W. Skelton, O. V. Shishkin, T. S. Teplytska, Eur. J. Inorg. Chem. (2003) 1426.

[197] B. Chiari, A. Cinti, O. Piovesana, P. F. Zanazzi, Inorg. Chem. 34 (1995) 2652.

[198] F. A. Mautner, H. Krischner, Monatsh. Chem. 123 (1992) 325.

[199] S. Subramanian, M. J. Zaworotko, Angew. Chem. Int. Ed. Engl. 34 (1995) 2127.

[200] S. Noro, R. Kitaura, M. Kondo, S. Kitagawa, T. Ishii, H. Matsuzaka, M. Yamashita, J. Am. Chem. Soc. 124 (2002) 2568.

[201] F. Calderazzo, U. Englert, G. Pampaloni, V. Passarelli, G. Serni, R. Wang, Can. J. Chem. 79 (2001) 495.

[202] S. S. Nagapetyan, E. R. Arakelova, Y. R. Zabrodskii, T. V. Kindyakova, V. M. Koshkin, A. P. Mil'ner, T. L. Slonskaya, Y. T. Struchkov, V. E. Shklover, Zh. Neorg. Khim. 35 (1990) 360.

[203] A. L. Spek, J. Appl. Cryst. 36 (2003) 7. 